\title{
Development of Structural Characterisation Tools for Catalysts
}

\author{
J. Lynch ${ }^{1}$ \\ 1 Institut français du pétrole, division Physique et Analyse, \\ 1 et 4 , avenue de Bois-Préau, 92852 Rueil-M almaison Cedex - France \\ e-mail: john.lynch@ifp.fr
}

Résumé - Développement d'outils de caractérisation structurale de catalyseurs — Les catalyseurs hétérogènes industriels, de par la diversité de leur composition et de leur structure ainsi que des différents traitements nécessaires pour les rendre actifs, présentent un défi majeur pour les techniques de caractérisation structurale.

La microscopie électronique fournit des informations en termes de texture et de structure à l'échelle de la particule élémentaire. Nous avons pu mettre en évidence des phénomènes d'épitaxie entre particules nanométriques et support, et déterminer les faces cristallographiques exposées. L'analyse élémentaire permet de contrôler la composition de particules individuelles dans un catalyseur bimétallique. Cette technique se heurte à des limitations si l'on cherche à caractériser la réactivité et la structure des catalyseurs à l'échelle atomique. Les méthodes d'analyses globales, telles que l'absorption et la diffraction des rayons $\mathrm{X}$, permettent d'étendre la gamme d'informations disponibles.

L'analyse de la structure fine des seuils d'absorption X nous a permis de caractériser des particules de taille inférieure au nanomètre dans des catalyseurs à base de platine et de mettre en évidence directement l'interaction entre le métal et des gaz réactifs : hydrocarbure et $\mathrm{H}_{2} \mathrm{~S}$. Les différences démontrées dans le comportement de solides monométalliques et bimétalliques constituent une base structurale pour l'explication des différences de réactivité des catalyseurs.

La diffraction des rayons $\mathrm{X}$, combinée à la microscopie électronique et à la spectroscopie de résonance magnétique nucléaire, met en évidence différents types d'aluminium extra-charpente dans des zéolithes soumises à un traitement hydrothermal. Nous avons quantifié une partie de ces espèces et caractérisé leur réactivité vis-à-vis de différents agents de désalumination.

Des études en cours montrent l'intérêt d'une combinaison de la diffraction et l'absorption des rayons X pour le suivi de la décomposition des hydrotalcites en oxydes mixtes ainsi que les possibilités d'étude par spectroscopie infrarouge de la molécule sonde CO des espèces superficielles dans les catalyseurs FischerTropsch.

L'emploi de cellules adaptées à l'analyse in situ permet une description détaillée des modifications structurales des catalyseurs sous atmosphères réactives et ouvre des possibilités de corrélations entre leur structure et leur activité catalytique. 


\begin{abstract}
Development of Structural Characterisation Tools for Catalysts - Because of the diversity of their compositions and structures, and the treatments needed to render them active, heterogeneous catalysts present a major challenge in structural characterisation.

Electron microscopy provides textural and structural information at the scale of the individual particle. We have been able to analyse expitaxial relationships between nanometer size particles and their support and to determine which crystal faces are most exposed. Chemical analysis can be carried out on individual particles in a bimetallic catalyst. Limitations of this technique are shown for characterisation of catalysts at the atomic scale or in reactive conditions. Here, global analysis methods based on X-ray absorption and diffraction provide more information.

$X$-ray absorption fine structure analysis has been applied to sub-nanometer size particles in platinum based catalysts to explore interactions between the metal and reactive gases such as hydrocarbons and $\mathrm{H}_{2} \mathrm{~S}$. Differences observed between monometallic and bimetallic solids lead to structural models to explain differences in catalyst reactivity.

$X$-ray diffraction, combined with electron microscopy and nuclear magnetic resonance spectroscopy, shows the presence of different forms of extra-framework aluminium in steamed zeolites. Quantification of some these forms has been possible and a study of their reactivity towards different dealumination agents has been achieved.

Work in progress shows the advantages of a combination of $X$-ray diffraction and absorption to study decomposition of hydrotalcites to form mixed oxides as well as possibilities in infrared spectroscopy of adsorbed $\mathrm{CO}$ to determine surface sites in Fischer-Tropsch catalysts.

Use of in situ analysis cells enables a detailed description of catalyst structure in reactive atmospheres and opens the possibility of correlating structure with catalytic activity.
\end{abstract}

\section{IN TRO DUCTIO N}

The aim of this article is to illustrate recent research in the Physics and Analysis Division of the Institut français du pétrole into methods for the structural characterisation of catalysts. It has been adapted from a report proposed to obtain the habilitation à diriger des recherches of the université Pierre et Marie Curie (Paris VI).

It is common to think about the problem of catalyst characterisation beginning from the global scale (elemental analysis, phase identification, etc.) before considering local analysis (distribution of phases, segregation, presence of defects). In the present work, we will consider the reverse order. By looking at the information derived from and the problems encountered in microanalysis of industrial heterogeneous catalysts in the transmission electron microscope (TEM), we can get a better idea of the contribution of global analysis techniques. Structural investigation methods such as extended X-ray absorption fine structure (EXAFS) and X-ray absorption near edge structure (XANES), X-ray diffraction (XRD) as well as infrared spectroscopy (IR) and nuclear magnetic resonance (NMR), can eliminate many of the uncertainties remaining from microanalysis of this type of solid.

Useful catalytic materials are required to have a high surface area, implying a high surface/volume ratio and/or very small particle sizes ( 1 to $10 \mathrm{~nm}$ equivalent to 100 to 10 percent of atoms exposed at the surface). Active phases and added promoters are deposited on a support of poorly crystallised oxide at low loading (in the case of precious metals, for instance, less than $1 \% \mathrm{wt}$ ). Basic research in adsorption, coadsorption and desorption on well characterised monocrystalline surfaces of metals and alloys has shown the influence of geometric, crystallographic and electronic effects on the catalytic activity and selectivity in model reactions. The extension of these concepts and correlation of results from model reactions and surfaces with the performance of industrial systems requires detailed characterisation of the latter and indeed implies research into the tools of analysis so as to adapt the technique to the desired information.

Industrial catalysts present a large degree of variety in terms of composition, structure, required functions: they range from zeolites and mixed oxides to metals $(\mathrm{Pt}, \mathrm{Re}, \mathrm{Rh}$, $\mathrm{Pd}$...) and sulphides (Mo, Ni, Co...) supported by oxides. A combination of several characterisation techniques is necessary to obtain a coherent description of these solids. Preparing and activating these solids means treatment under reactive atmospheres (such as hydrothermal treatment, reduction, sulphidation). A description of the active phase thus requires appropriate cells allowing analysis of specimens treated in conditions similar to those used industrially. These requirements, a multitechnique approach and the development of in situ analysis tools, have formed the basis for a long term research programme in characterisation of industrial heterogeneous catalysts at IFP.

We begin by a description of the possibilities of local analysis by electron microscopy which can provide information in terms of texture and structure at the scale of the basic building blocks of catalysts. We will show evidence of 
epitaxy between nanometer sized metal particles and the alumina support and the possibility of determining the crystallographic faces developed in the case of thorine. Elemental analysis has allowed us to verify the bimetallic nature of individual particles in a Pt-Pd/alumina catalyst. This technique has its limitations if we want to characterise the reactivity and structure at the atomic scale of highly dispersed reforming catalysts or of zeolites containing extraframework species as isolated atomic clusters. Global analysis methods such as X-ray absorption and diffraction extend the range of available information.

Analysis of the fine structure at X-ray absorption edges enables characterisation of particles of size less than one nanometer in platinum based catalysts and can be used to observe the interaction between the metal and reactive gases: examples are given for a hydrocarbon molecule and for $\mathrm{H}_{2} \mathrm{~S}$. The observed differences in behaviour of mono- and bimetallic solids form a structural basis for the explanation of differences in the reactivity of these catalysts.

X-ray diffraction, combined with electron microscopy, shows the existence of different types of extra-framework aluminium in zeolites after hydrothermal treatment. We have been able to quantify part of these species and determine their reactivity vis-à-vis different dealuminating agents.

The most recent studies show the possibilities of a combination of X-ray diffraction and absorption to follow the decomposition of hydrotalcites into mixed oxides and the interest of carbon monoxide as a molecular probe in infrared spectroscopy for the study of surface species in FischerTropsch catalysts. The detailed in situ description of structural modifications under reactive atmospheres is possible using appropriate cells, opening the possibility of correlating structure with catalytic activity.

\section{LOCAL AN ALYSIS BY AN ALYTICAL ELECTRON MICRO SCOPY}

In the 1980's, the application of transmission electron microscopy (TEM) to highly divided systems achieved important progress thanks to the availability of new electron sources. With classic TEM electron sources, heated tungsten filaments, an intense electron beam can be brought to a focus in an area of the order of a micron in diameter. However, their low brilliance (of the order of $10^{4} \mathrm{~A} / \mathrm{cm}^{2} / \mathrm{sr}$ ) limits the possibility of concentrating this beam into a probe of a few nanometers in size, due to the resulting important loss in intensity. Developments in ultrahigh vacuum at the end of the 1970's allowed the introduction of the field emission gun (FEG) for the production of electrons. The brilliance of this type of source is extremely high $\left(10^{10} \mathrm{~A} / \mathrm{cm}^{2} / \mathrm{sr}\right)$. This means that it is possible to form a probe of nanometer dimensions with enough current to allow imaging, diffraction, and chemical analysis (the latter either by induced X-ray spectroscopy or analysis of the transmitted electrons). Together these facilities are known as "analytical microscopy electron".

\subsection{Imaging}

The major, indeed the principal, use of TEM is of course the direct observation of specimen texture. In high resolution imagery it is possible, under certain conditions, to visualise crystalline structure at detail close to the atomic level (about $0.2 \mathrm{~nm}$ ). This however requires an extremely precise orientation of the crystal with respect to the incident beam. As we shall see, this is difficult in the case of catalysts due to time limitations on observation imposed by their fragility under the impact of the beam. In the examples treated here, imagery will be used essentially to identify the zones analysed.

\subsection{Microdiffraction}

The prototype of the first commercial instrument using a FEG for analytical microscope (the VG HB5) was developped in the University of Cambridge (UK) by the team of professor A. Howie. We will first present results covering metallurgical applications of microdiffraction in analytical electron microscopy. A theoretical analysis of the formation of microdiffraction patterns showed [1] the possibility of local measurement of specimen thickness and of the parameter representing the interaction with the electron beam, known as the extinction distance. Simulation of microdiffraction patterns and comparison with experiment allowed a determination of the precision in these measurements, of the order of $10 \%$ relative.

The main aim of the project was to follow the formation of precipitates during the heating of $\mathrm{Al}-1.2 \%\left(\mathrm{Mg}_{2} \mathrm{Si}\right)$ alloys, materials used in the production of high resistance tubing [2]. After quenching and heat treatment, the alloy is hardened by precipitates of the stable $\beta$ phase, of face centred cubic structure and of composition $\mathrm{Mg}_{2} \mathrm{Si}$, in the form of rectangular platelets. Previous studies of precipitate morphology showed that precipitation of the $\beta$ phase was preceded by the formation of needle shaped Guinier-Preston zones (segregation of minority elements in a volume remaining structurally coherent with the matrix), followed by the growth of rods (the so called $\beta$ ' phase) of nanometer dimension. The crystallographic structure of the $\beta$ ' phase was somewhat of a puzzle, several models having been proposed. Diffraction patterns form a single precipitate obtained by microdiffraction simplified the structural analysis. Figure 1 illustrates orientations of the precipitates, parallel to the [100] axes of the aluminium matrix, and a diffraction pattern from a single precipitate. The positions of diffraction spots from the matrix are indicated for comparison. The analysis confirms a hexagonal structure model for the rod shaped precipitates. 

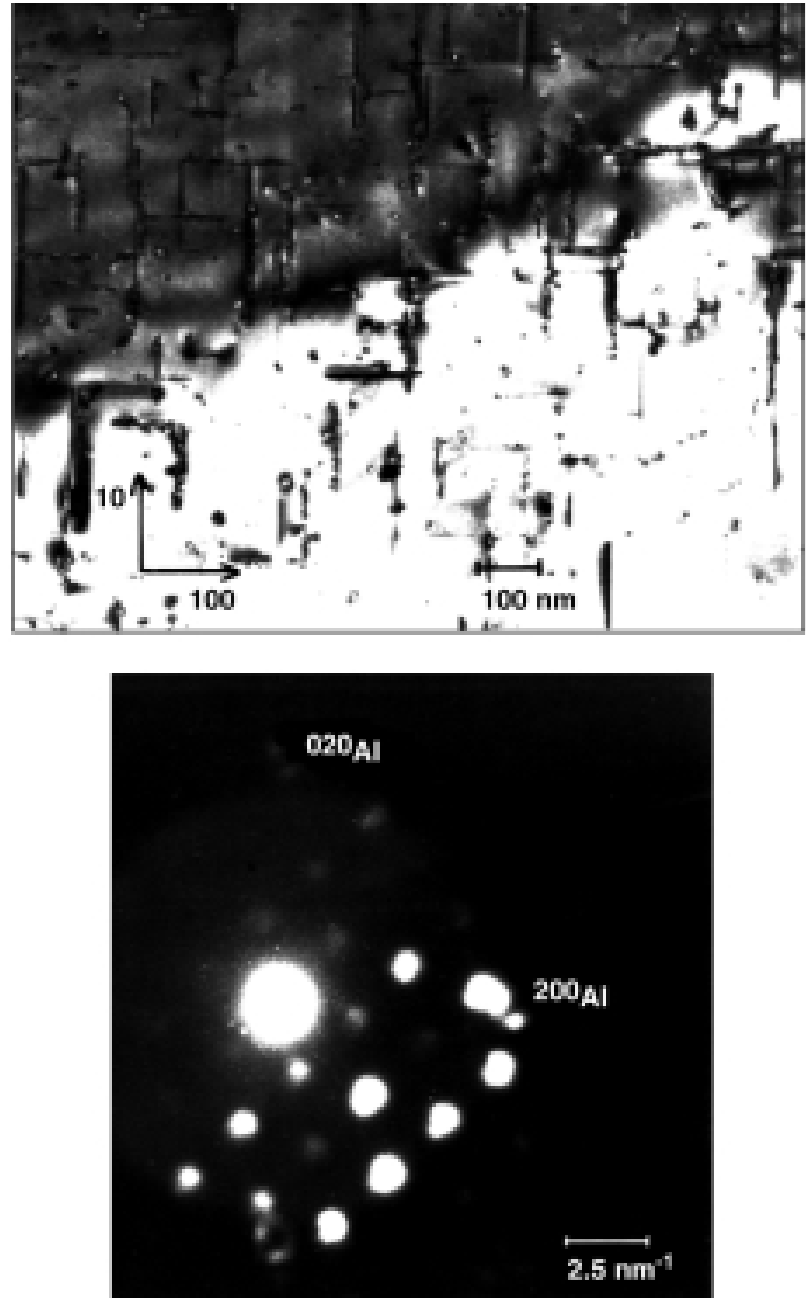

Figure 1

Precipitates in an $\mathrm{Al}-1.2 \%\left(\mathrm{Mg}_{2} \mathrm{Si}\right)$ alloy. The (001) zone axis image of the matrix shows precipitate orientation whilst the diffraction pattern of a single precipitate shows the hexagonal structure.

\subsection{Elemental Analysis}

In parallel to the use of microdiffraction to obtain structural information, a nanometer scale probe allows analysis of the local chemical composition by spectroscopy of X-rays induced by the electron beam (X-ray emission spectroscopy or XES). In the case considered here, separate elemental analysis of the precipitates, surrounded by the matrix, was not possible. Induced X-ray spectroscopy did however reveal [3] that the $\beta$ ' precipitates were $\mathrm{Mg}$ poor $(\mathrm{Mg} / \mathrm{Si}=0.4$ compared with 2 in the stable phase). Figure 2 compares the spectrum obtained on a stable precipitate of composition $\mathrm{Mg}_{2} \mathrm{Si}$ with that of the $\beta$ ' phase.

An example of elemental analysis by electron energy loss spectroscopy (EELS) is provided by work with the team of
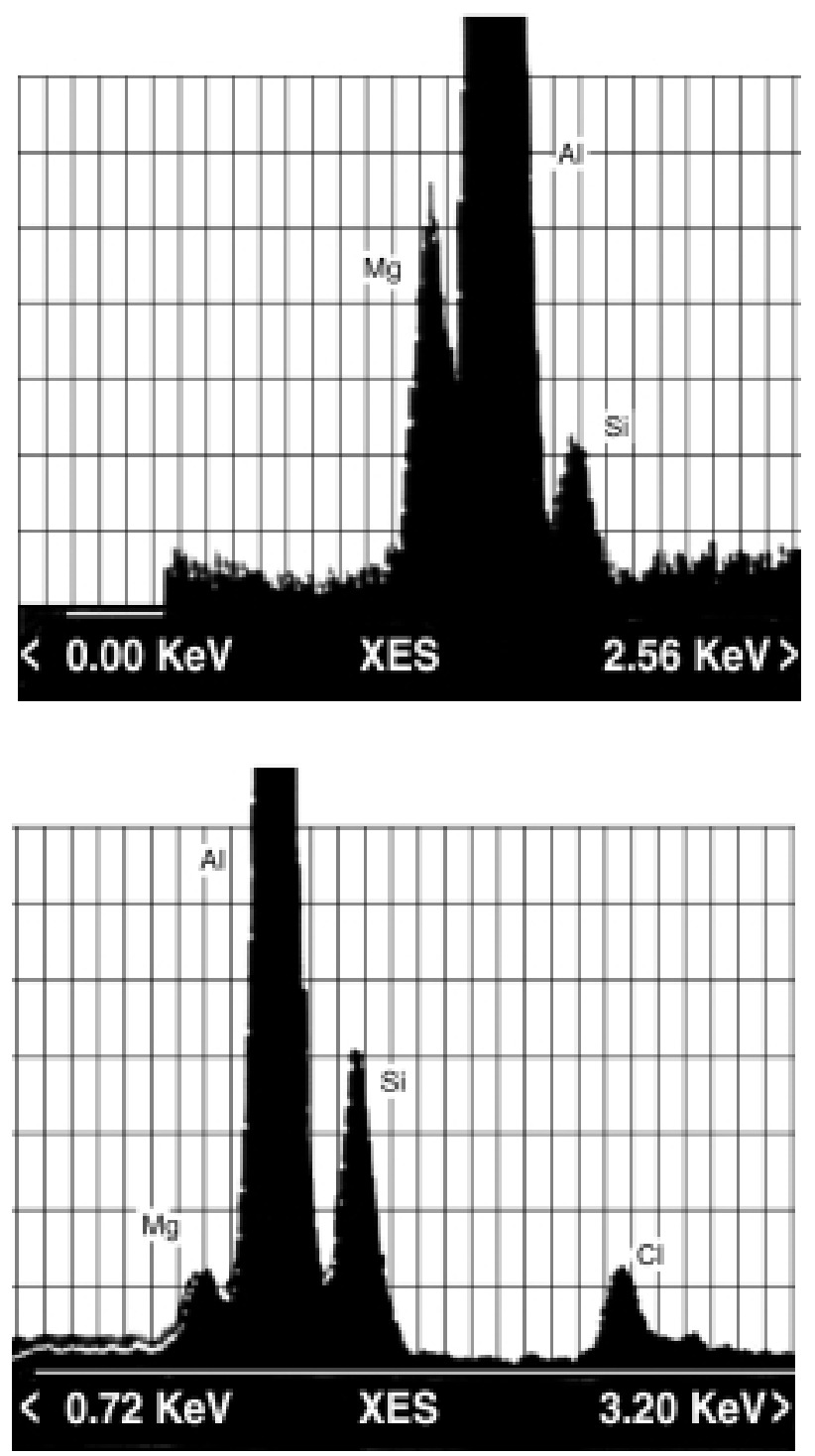

Figure 2

Induced X-ray analysis in an $\mathrm{Al}-1.2 \%\left(\mathrm{Mg}_{2} \mathrm{Si}\right)$ alloy. Analysis of a precipitate of the stable phase shows an atomic $\mathrm{Mg} / \mathrm{Si}$ ratio of two. Analysis of a precipitate of the $\beta$ ' phase shows the latter to be poor in $\mathrm{Mg}$.

J. Cowley and J. Spence at Arizona State University. By combining imagery and EELS, it was possible (Fig. 3) to locate the atomic plans containing specific atoms $(\mathrm{Ba})$ inside the crystallographic structure of a solid $\left(\mathrm{BaAl}_{2} \mathrm{O}_{6}\right)$ of large unit cell dimensions [4].

\subsection{Instrumental Research in Microdiffraction}

Two modes of microdiffraction pattern collection are possible. The classical detection system for the VG HB5 microscope is sequential [5]. Here, the electrons forming the pattern are scanned by electrostatic coils in front of the 

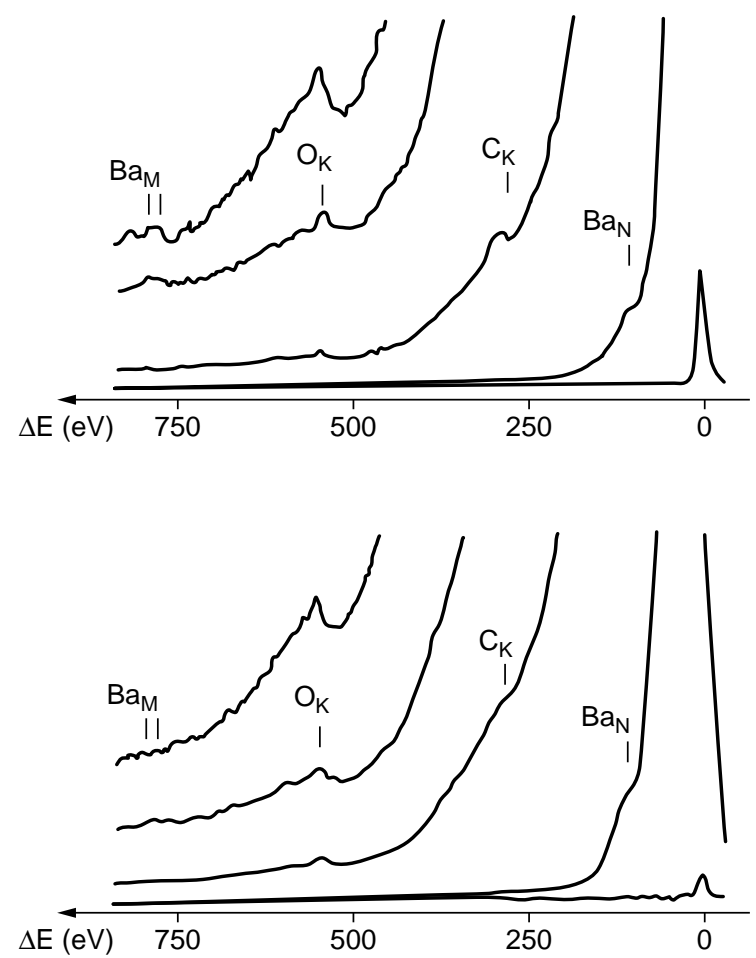

Figure 3

Electron energy loss spectra from regions separated by $1.1 \mathrm{~nm}$ in a crystal of $\mathrm{BaAl}_{2} \mathrm{O}_{6}$. Each spectrum is represented at several scales to show up all edges. The intensity of the barium $\mathrm{M}$ edge varies with position in the unit cell of the structure.

entrance slit of a photomultiplier detector. Scanning the pattern imposes an acquisition time of the order of a minute. Solids such as the transition aluminas used as catalyst supports are destroyed by the electron beam during this time. A prototype detector, developed at the Institut français $d u$ pétrole, uses a second acquisition mode, with parallel detection. Here, the entire pattern is collected at one time. As shown in Figure 4, the electron diffraction pattern is converted to its optical analogue on a phosphor screen which is then photographed, via a mirror. Despite the advantage of parallel detection, the low collection efficiency of the photographic plate made the system impracticable, with collection times of several minutes. The use of more modern detection systems, in particular an image intensified video camera, allowed this collection mode to be used to its full advantage. This system allows diffraction patterns to be recorded at video rates [6]. One original aspect is the possibility, by introducing a central hole in the converter screen, to observe simultaneously the image and the associated diffraction pattern [7-9].

The group of microanalysis techniques described in this section open several interesting possibilities in the study of divided systems and in particular of catalysts $[10,11]$. In the

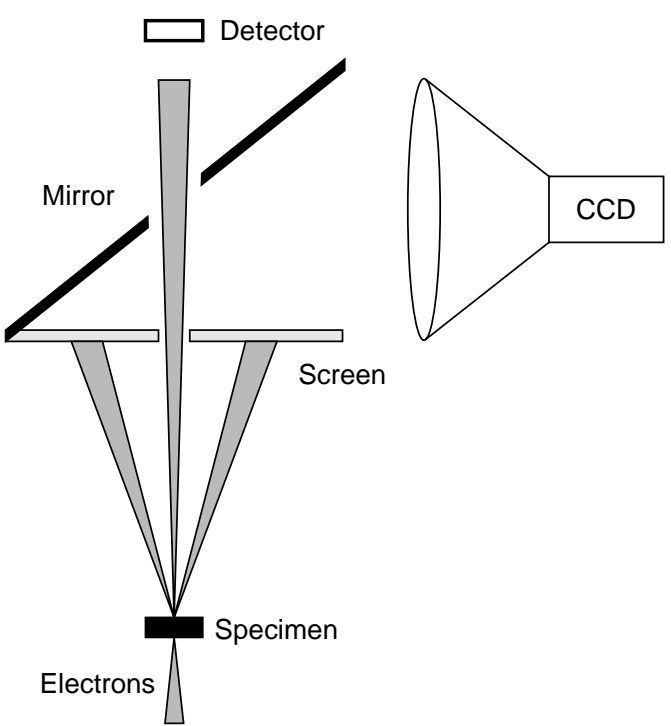

Figure 4

"Parallel" collection of microdiffraction patterns. The electron diffraction pattern is converted to its optical equivalent, recorded by $\mathrm{CCD}$ video camera.

next section, we describe in detail some applications on solids similar to industrial catalysts.

\subsection{Local Analysis of Catalysts}

Because of their high active surface, catalysts often consist of nanometer sized particles. Their characterisation by conventional microscopy raises problems in the extraction of structural and chemical information. Selected area electron diffraction, covering an area of the order of a micron, shows diffraction rings, with contributions from numerous particles. This makes it difficult to verify the presence of defects or of structural relationships between particles and their support. Chemical analysis, at the micron scale by the electron microprobe or globally by X-ray fluorescence, is indispensable to verify the preparation. However, the homogeneous presence of two metals in areas a micron in diameter cannot guaranty the existence of nanometer size bimetallic particles.

For most catalytic solids (metals and sulphides supported on transition aluminas, finely divided oxides, etc.) the preparation and observation present few problems [12]. A simple example is given by an image (Fig. 5) of a delaminated clay showing creation of new texture which is related to differences in absorption properties for large molecules [13].

Zeolites are synthesised in a form that requires a special preparation technique. These solids crystallise with particle sizes of the order of a micron, making them electron opaque. We have applied [14] a preparation technique using an ultramicrotome to obtain thin sections of zeolites. These thin 


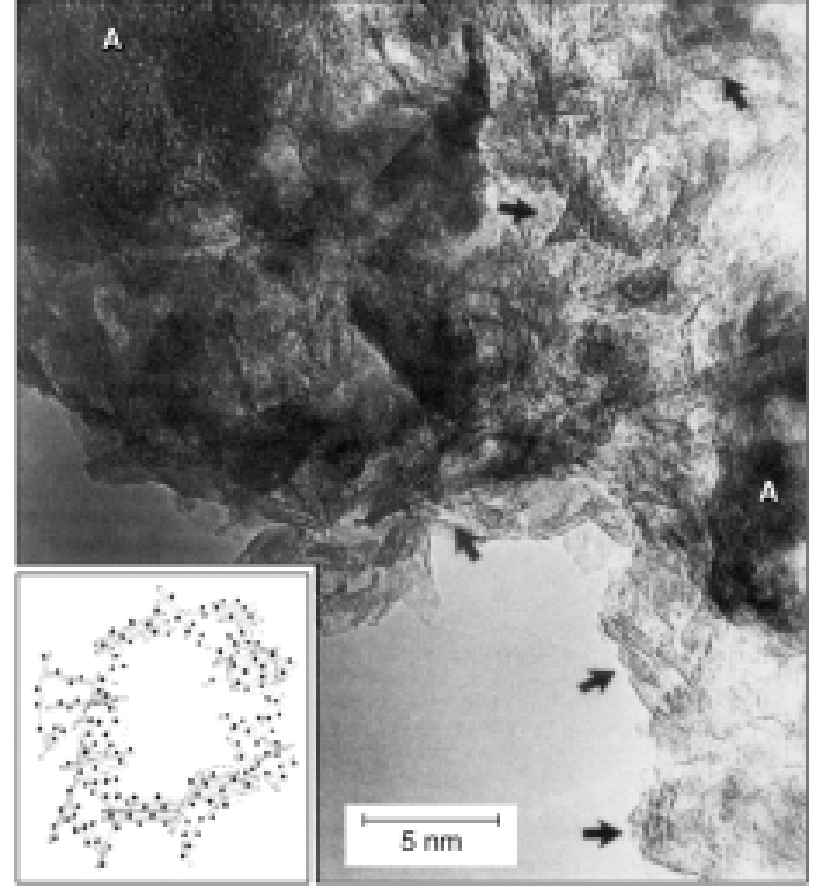

Figure 5

TEM image of a clay delaminated by insertion of alumina aggregates. The clay layers form a "house of cards" network giving rise to mesoporosity. Zones marked "A" contain amorphous alumina.

sections allow the structure to be seen in detail in the TEM, whilst at the same time conserving the texture of the grains. The example in Figure 6 is from a study of the synthesis of zeolite $\beta$ [15]. Growth defects can clearly be seen, both in the structural image and in the electron diffraction pattern. These defects strongly affect access to the internal porosity of the zeolite [16].

With the spatial resolution of microdiffraction it has been possible to obtain diffraction patterns from nanometer sized particles typical of monocrystals showing zone axes, and thus the orientation with respect to the optic axis. We were able to explore (Fig. 7) [17] epitaxial relationships formed between metal particles and the support as a function of preparation conditions.

Using the observation that preferential orientation is imposed on particles by sedimentation on an amorphous carbon film, it was possible to carry out a statistical survey of the exposed faces of thorium oxide (Fig. 8) [18]. By correlation between these microstructural results and infrared spectroscopy of the hydroxyl surface groups, the IR bands could by attributed to different environments of the $\mathrm{OH}$ species. The stability and reactivity of these groups depend on their structure and on their local arrangement on the surface.

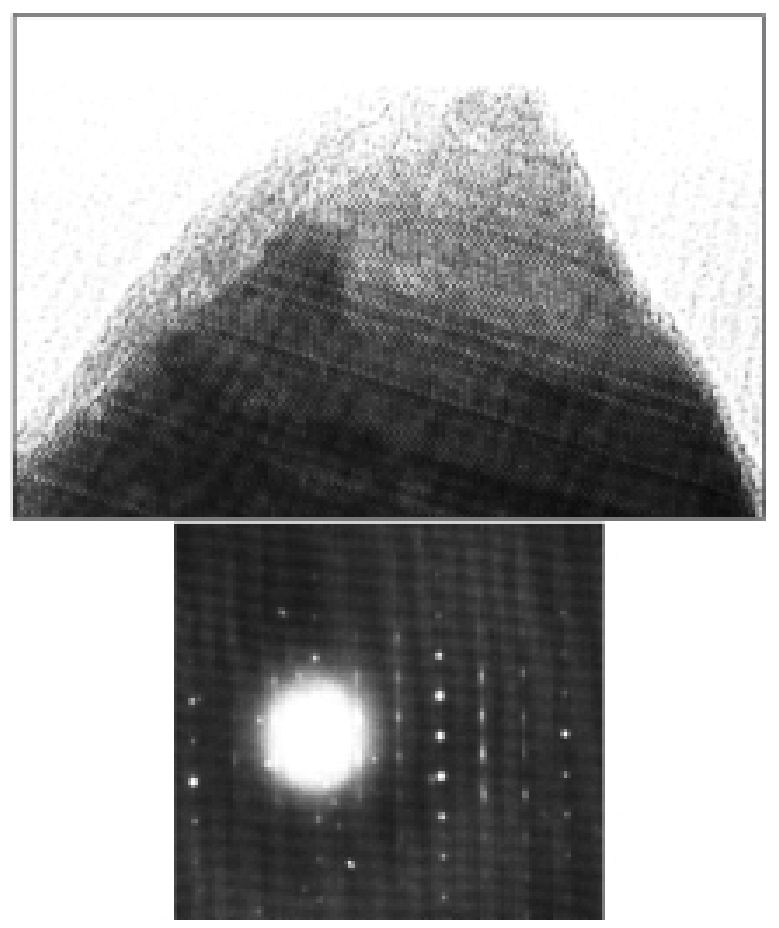

Figure 6

TEM image and electron diffraction pattern of zeolite $\beta$. Growth defects, visible in the micrograph, result in streaks in the diffraction pattern corresponding to the growth direction.

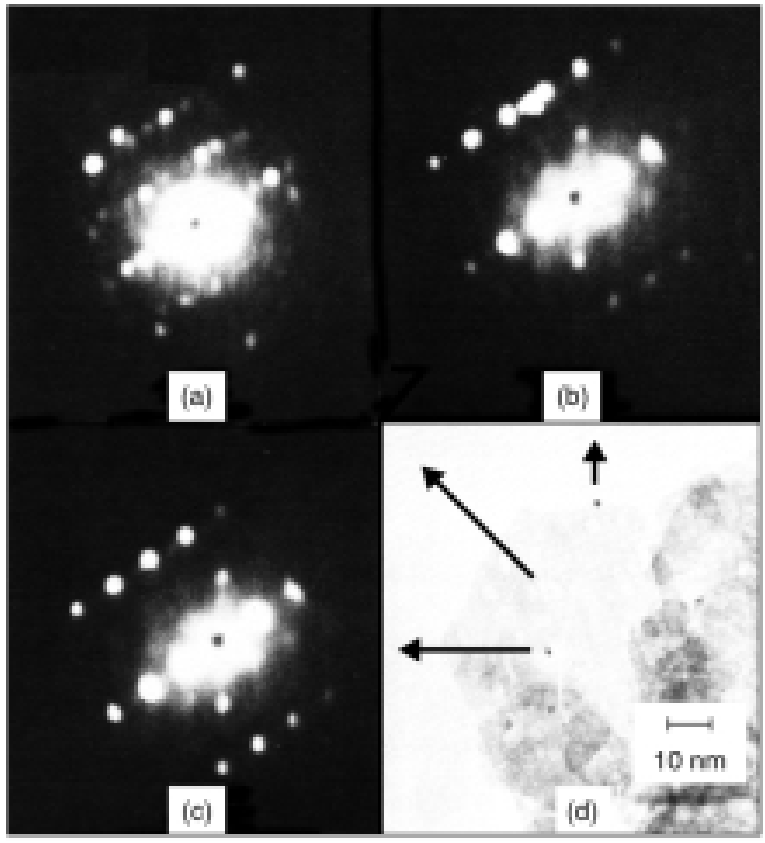

Figure 7

Epitaxy between Pd particles and their alumina support as revealed by microdiffraction. Individual patterns of two particles (b and c) show similar orientation. Several crystallographic directions coincide with those of the alumina support (a). 
110
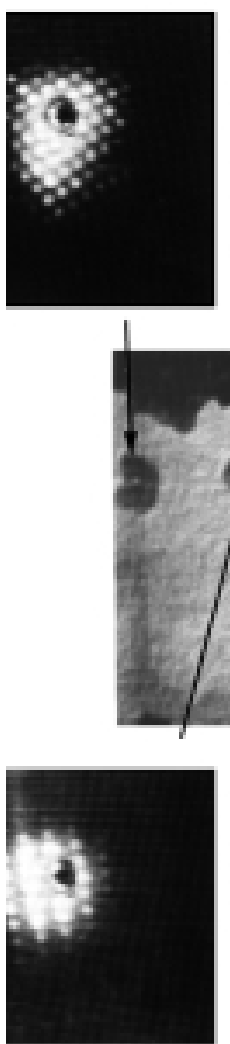

111
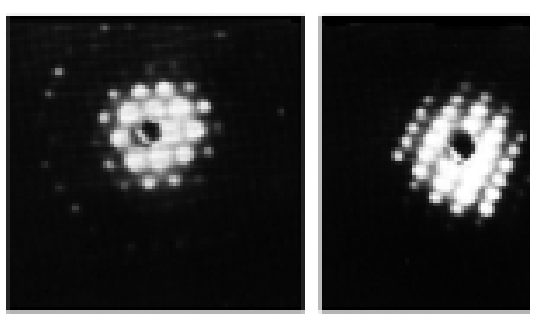

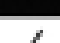

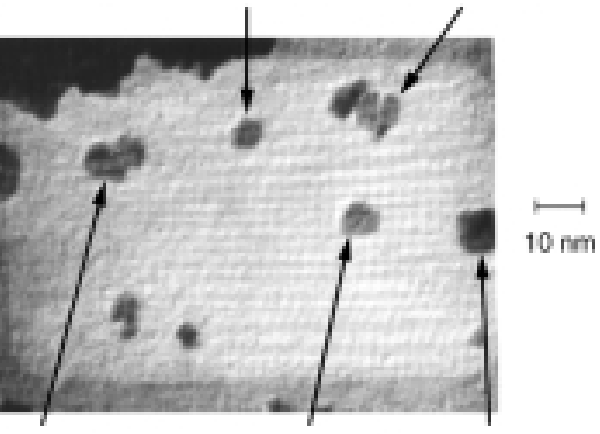

211

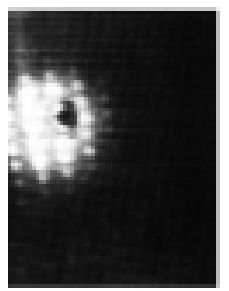

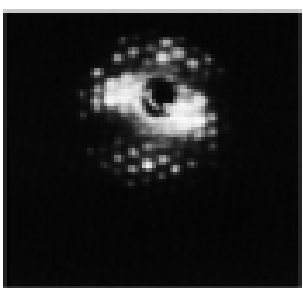

110

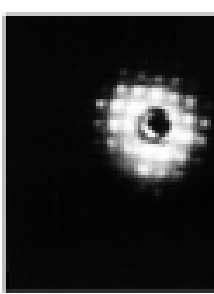

100
Figure 8

Microdiffraction shows the orientations of individual particles of $\mathrm{ThO}_{2}$ on an amorphous carbon film and allows exposed crystal faces to be determined.
The strength of FEG based analytical electron microscopy appears most clearly when we consider microanalysis by XES [19]. An example concerns bimetallic Pt-Pd catalysts. The aim in preparing catalysts of this type is of course to associate the two metals in the individual particles. Only by a particle by particle analysis, made possible by this type of source, can the quality of preparation be tested for these solids. We were able to demonstrate [20], as shown in Figure 9, that the classic preparation route leads to some particles (approx. 50\%) of pure platinum.

We have developed the possibilities of elemental analysis by X-rays, both in terms of quantification of the results [21], and by correlating individual particle analysis and the micron scale analysis in the electron microprobe [22]. This type of comparison allows us to link up different scales of observation in elemental analysis.

EELS analysis of supported metal particles is also possible, as shown in Figure 10. Here simultaneous analysis of induced X-rays and energy loss electrons from an individual $2 \mathrm{~nm}$ diameter particle shows comparable count rates. EELS has the added advantage of sensitivity to light elements such as oxygen and carbon.

\subsection{The Limits of Analytical Microscopy}

The successful application of microdiffraction and elemental microanalysis at the nanometer scale to the study of catalysts led us to attempt a definition of the limits of these techniques $[23,24]$. One clear and important limitation for catalysts studies is the ex situ nature of the analysis. TEM specimen preparation usually implies a contact with air, which will

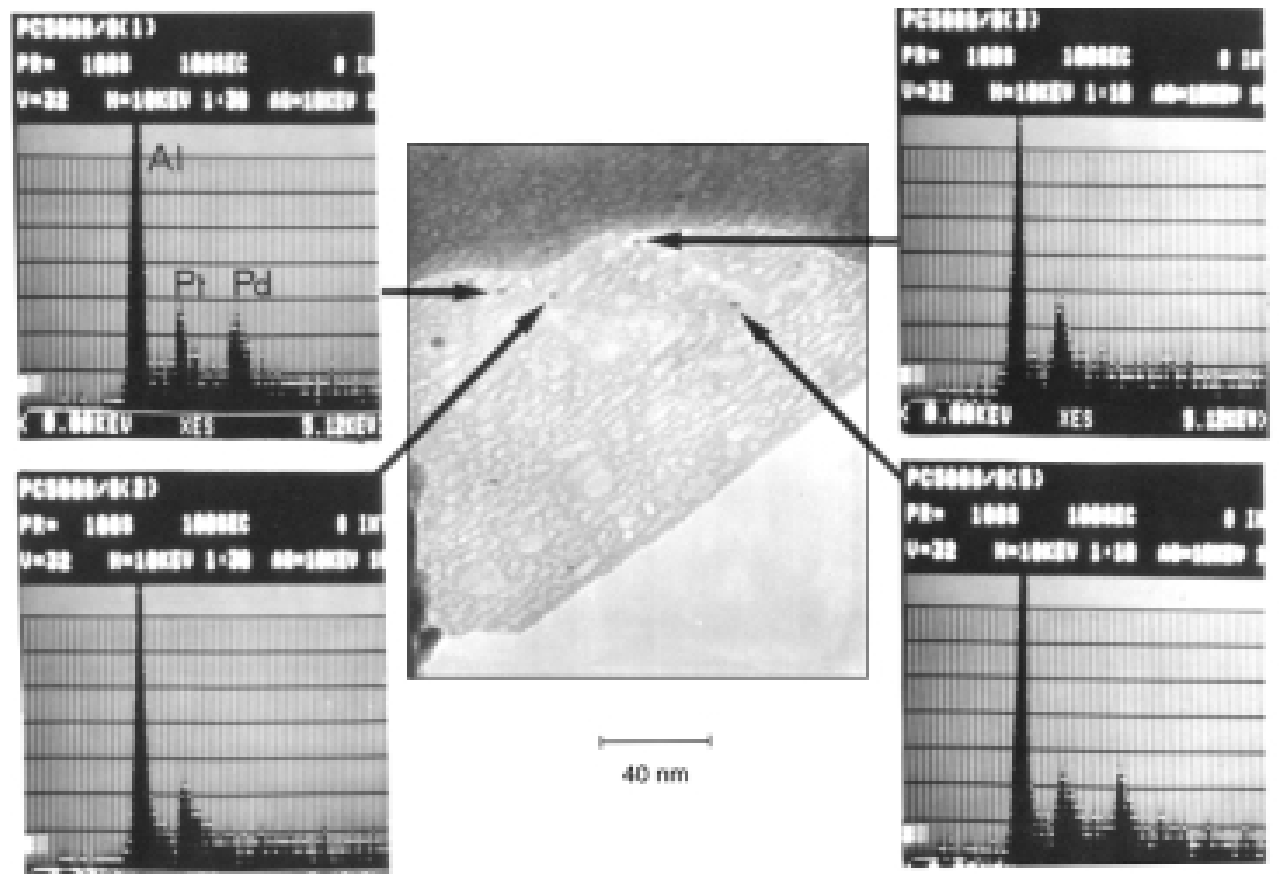

Figure 9

The mono- or bimetallic nature of nanometer scale particles in a $\mathrm{Pt}-\mathrm{Pd} / \mathrm{Al}_{2} \mathrm{O}_{3}$ catalyst can be determined by analysis of X-rays produced. 

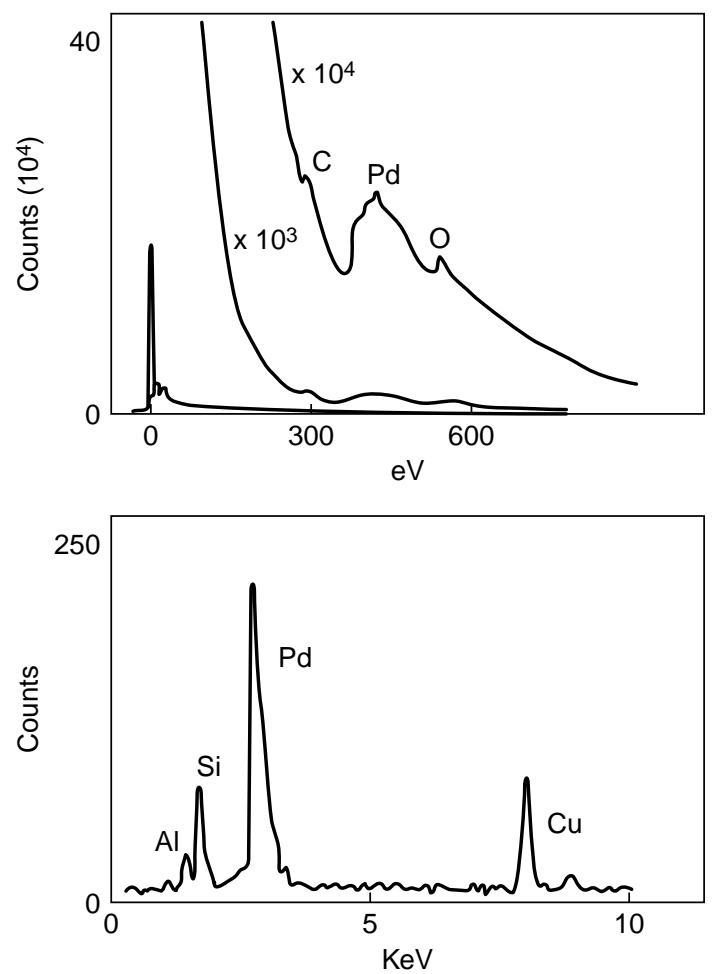

Figure 10

Comparison of electron energy loss (EELS) and X-ray emission (XES) spectra from a $2 \mathrm{~nm}$ Pd particle supported on zeolite. In XES, the copper signal is due to excitation of the specimen support grid.

oxidise the surface of the solid and risk provoking major modifications of the metal phase consisting of nanometer scale particles. Although it is possible, thanks to the development of transfer cells [25], to avoid air contact, the TEM, operating under high vacuum, remains essentially an ex situ technique. It is not for instance possible to follow the modifications to a solid during treatment under reactive gases whilst maintaining high resolution.

Other limitations more specific to catalysts became evident during our studies. The density of energy produced by the FEG, essential in the production of exploitable signals from nanometer sized zones, is enormous [26]. One can estimate that, for a probe current of $1 \mathrm{nA} / \mathrm{nm}^{2}$ and an electron energy of $100 \mathrm{keV}, 10^{8} \mathrm{~W} / \mathrm{mm}^{2}$ are deposited in the sample. This density of energy is sufficient to induce structural modifications in particles, visible on the video time scale of the microdiffraction data collection system [27]. For nanometer sized particles, the electron bombardment in the time period required for acquisition of an XES spectrum (1 to 2 min) can destroy the crystallographic structure [28].

Our studies, and those of others working in high resolution TEM, have shown that the identification and structural analysis of sub-nanometer particles is limited due to interference from the support [29]. Figure 11 illustrates this in the case of platinum supported on transition alumina. When the microscope is used at maximum resolution to visualise the crystallographic structure of the solid, the contribution from the support dominates. Only by eliminating some structural information in order to give preference to chemical information (due to differences in diffusing power) can we detect very small platinum particles. This means of course that the TEM will not in general allow a full structural study of small supported particles.

Similar problems are observed in the TEM study of zeolites. Imagery and electron diffraction can provide interesting information on the internal texture of these solids and show up the presence of structural defects. However, their fragility under electron bombardment makes it difficult to obtain the structural image that would be needed for an atomic scale description of the defects. Adsorption proprieties of zeolites are strongly influenced by the nature and position of cationic species, but the contrast due to the presence of these species is too low compared to that of the zeolite framework to allow their study by TEM.

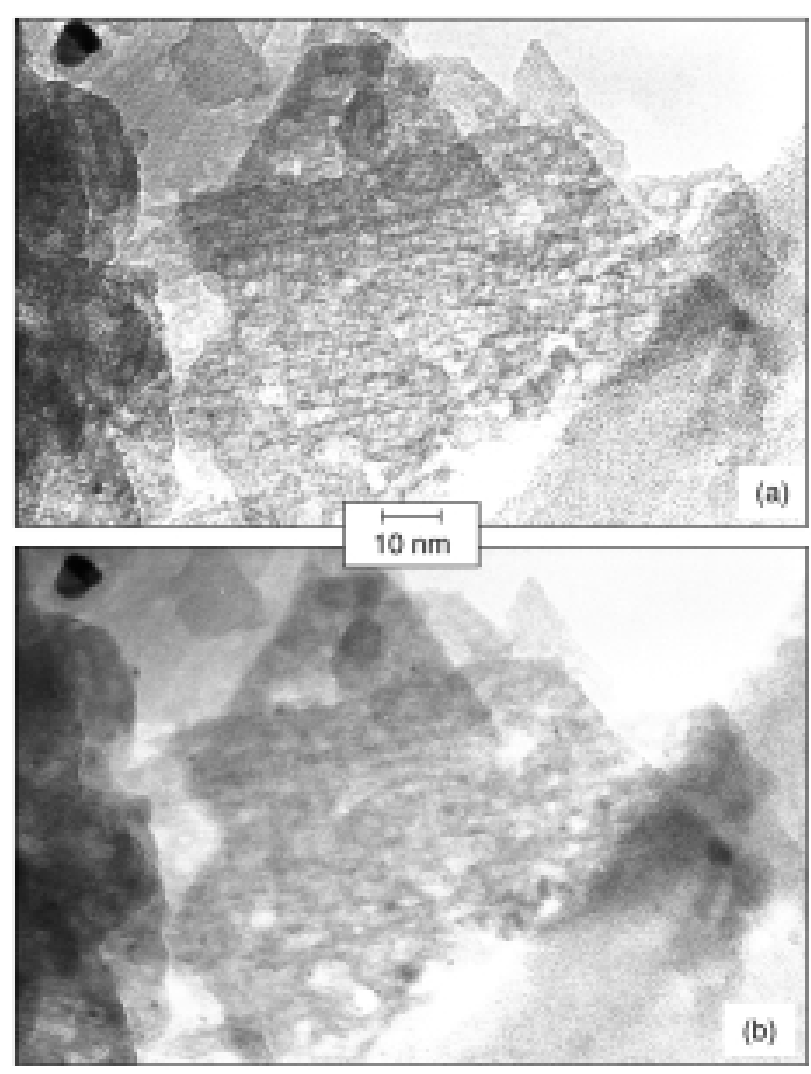

Figure 11

Images of nanometer sized particles in a $\mathrm{Pt} / \mathrm{Al}_{2} \mathrm{O}_{3}$ catalyst. In (a), the observation conditions allow structure visualisation. This image is dominated by the contribution from the support. In (b), the contrast from the metallic particles is higher but the structural information is missing. 
EELS spectroscopy can potentially give interesting information on the local environment of elements present in a catalyst particle, from analysis of the spectral fine structure. However, the large number of edges present in the spectral region of interest $(<1000 \mathrm{eV})$ limits the useful range of energy to a few tens of electron volts after the edge (see Fig. 10). Only in the region above several keV does the edge separation allow analysis of local structure. This is the area of predominance of EXAFS, a technique we shall consider in the next section.

We have seen that analytical microscopy electron is a powerful tool, allowing direct visualisation of the texture and, in certain cases, the structure of catalysts. Local analysis modes such as microdiffraction and induced X-ray spectroscopy add to the available information on the structure and composition of small supported particles. To sum up the limitations of this technique when catalysts are explored in detail:

- microscopy is a local technique that does not give a global vision of the specimen. Clearly, the examples cited here of analysis of particle orientations in $\mathrm{ThO}_{2}$ and compositional variation in Pt-Pd particles do not cover a statistically representative sample of the catalyst;

- the technique cannot in general be made selective for a given element or phase: the presence of a support prevents visualisation of very small particles;

- the probe used is potentially destructive: our studies show that the impact of an electrons beam can induce considerable damage on nanometer sized particles;

- finally, an important point for the study of catalysts, these analyses are carried out in ultrahigh vacuum. A doubt persists as to the relevance of the information in explaining catalytic properties observed under reactive gases, at temperature and pressure.

Many of these problems can be overcome by employing techniques based on the use of photons, and in particular of $\mathrm{X}$-rays. Such techniques can be both global (analysing a representative sample volume) and selective in terms of an element or a structure, they are in general not destructive and can provide information in situ under reaction conditions. In the following sections we will describe the application of $\mathrm{X}$-ray absorption spectroscopy to the case of highly dispersed particles and of X-ray diffraction to the case of zeolites.

\section{HIG HLY DISPERSED SUPPO RTED METALS}

X-ray absorption spectroscopy, developed by many synchrotron radiation centres, offers solutions to certain limitations of TEM. The extended fine structure of X-ray absorption edges, known as EXAFS, carries information on short range order around a target atom [30, 31]. This is particularly useful in the case of particles whose size is of the order of a nanometer. Using X-rays in the 5 to $25 \mathrm{keV}$ energy range opens the possibility of in situ studies, for instance during treatment under reactive gas. Electronic state information can also be obtained by analysing the near edge structure, or XANES [32, 33].

For this project, reaction cells were developed and used at the LURE synchrotron (Orsay) for the study of catalytic systems similar to industrial reforming catalysts [34].

\subsection{Towards a Description of the Active Phase}

The possibilities of EXAFS were explored via a microstructural study of $\mathrm{Pt} / \mathrm{Al}_{2} \mathrm{O}_{3}$ catalysts [35]. Industrial preparation of this type of catalyst uses hexachloroplatinic acid, $\mathrm{H}_{2} \mathrm{PtCl}_{6}$, as a precursor. This at the same time confers acidity to the support. The particle dispersion obtained depends on the loading of platinum and chlorine [36]. We wanted to know how platinum was fixed to the support and in particular whether different sites of fixation exist. In the study, we therefore varied systematically the concentrations of platinum and chlorine in the impregnation solution.

Analysis of the solids after drying showed the formation of $\mathrm{PtCl}_{4} \mathrm{O}_{2}$ complexes implying a strong interaction with the support. These complexes are mononuclear in the sense that we do not observe the presence of second atomic neighbours of platinum which would be characteristic of an extended structure. For platinum loadings of $0.3 \%$ to $1.5 \%$ wt (and for a chlorine concentration of $2.2 \%$ ) no variation in the platinum environment is observed (Fig. 12). Nor does the chlorine loading influence the platinum environment. There is therefore no evidence of different sites at which the complex formed by $\mathrm{H}_{2} \mathrm{PtCl}_{6}$ is anchored to the support. On calcining, the chlorine in the environment of platinum is progressively replaced by oxygen. Here again, no influence of loading can be detected.

Only after reduction of the solids can significant differences be observed for different loadings of $\mathrm{Cl}$ and $\mathrm{Pt}$ (Fig. 13). For a system containing $1 \%$ wt platinum, a lower $\mathrm{Cl}$ loading $(1.1 \%)$ leads to an average coordination number around the platinum $\left(\mathrm{N}_{\mathrm{Pt}-\mathrm{Pt}}\right)$ of 7.5 , corresponding to particles about $2 \mathrm{~nm}$ in diameter. For this solid, the particles are visible by TEM, confirming the size estimation by EXAFS. For the same Pt loading, but with $2.2 \% \mathrm{Cl}$, the value of $\mathrm{N}_{\mathrm{Pt}-\mathrm{Pt}}$ is 4 . It is possible to construct a model of the particle, coherent with this coordination number, containing only five $\mathrm{Pt}$ atoms. Here it is not possible in TEM to distinguish the contrast due to metallic particles from that of the support.

We have thus observed an increase in platinum dispersion with increasing chlorine loading. These resultants confirm the deductions of well-established techniques such as gas chemisorption. However, EXAFS indicates that the influence of chlorine loading is felt essentially at the stage where particles containing several platinum atoms are formed, during reduction. 


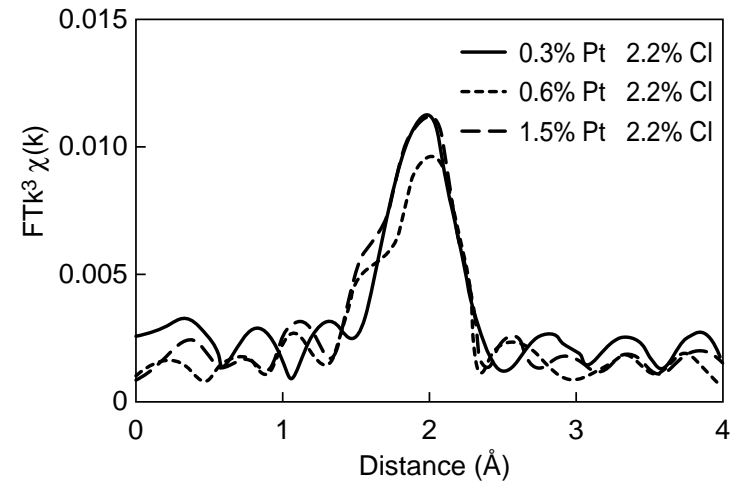

Figure 12

Fourier transforms of the EXAFS data from dried $\mathrm{Pt} / \mathrm{Cl}-$ $\mathrm{Al}_{2} \mathrm{O}_{3}$ catalysts. A similar environment of platinum is observed whatever the Pt loading.
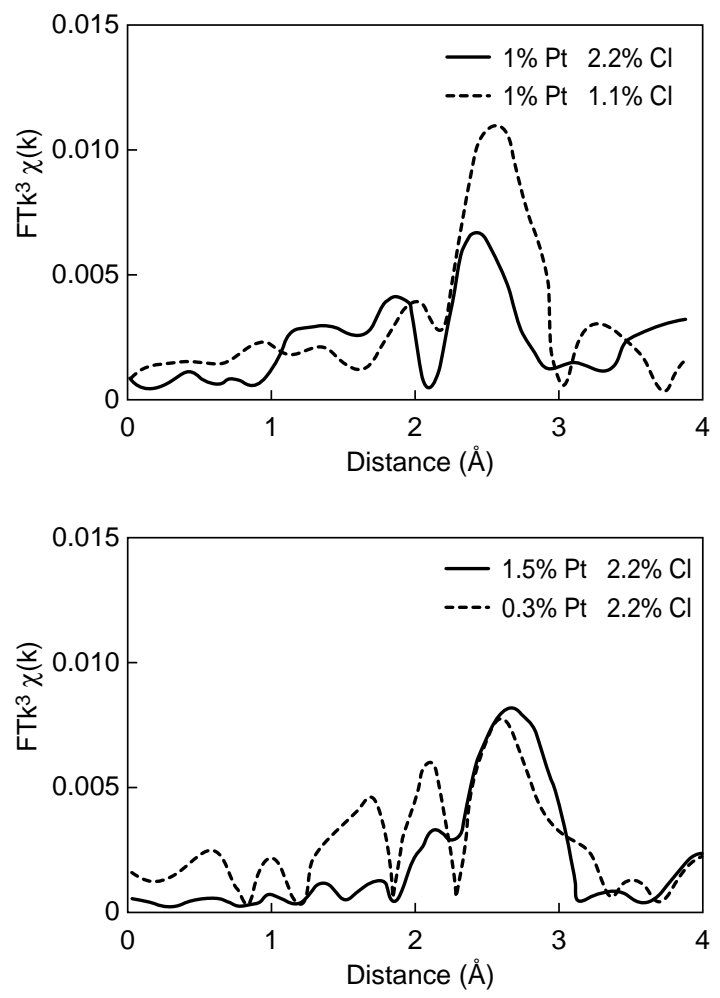

Figure 13

Fourier transforms of the EXAFS data from reduced $\mathrm{Pt} / \mathrm{Cl}$ $\mathrm{Al}_{2} \mathrm{O}_{3}$ catalysts. With increasing $\mathrm{Cl}$ content the platinum coordination number (and thus the metal particle size) decreases.

Variation of the platinum loading in the explored range does not influence the number of Pt-Pt neighbours detected. For low loadings $(0.3 \% \mathrm{wt})$, we do however begin to observe Pt-O bonds (Fig. 13, peak at $1.5 \AA$ ). The edge structure (XANES) for this solid confirms that the platinum is reduced. The oxygen atoms involved are probably from the support. We attributed the fact that these bonds are no longer detected for higher loading $(1.5 \% \mathrm{wt})$ to the existence of a variety of metal-oxygen distances. In fact this is probably not a true chemical bond: one can imagine the particles randomly placed on the support surface.

An alternative fixation method for platinum, which avoids the introduction of chlorine, uses platinum acetylacetonate, $\mathrm{Pt}$ (acac.) 2 . EXAFS results here again show formation of a well-defined complex with the support [37]. The Pt (acac.) 2 molecule looses one acetylacetonate group during impregnation and drying [38], but the platinum retains an environment of 4 oxygen atoms by bonding with 2 oxygen atoms of the support. After calcining at $493 \mathrm{~K}$ and loss of the second acetylacetonate molecule the environment is modified, two oxygen atoms now fix the Pt to the support. High temperature calcining of these chlorine free solids results in sintering, with formation (Fig. 14) of Pt-Pt distances $(0.7$ at $573 \mathrm{~K}, 4.2$ at $773 \mathrm{~K})$ typical of the bulk oxide phase.

This is coherent with the foregoing observation of the role of chlorine in the formation of dispersed particles.
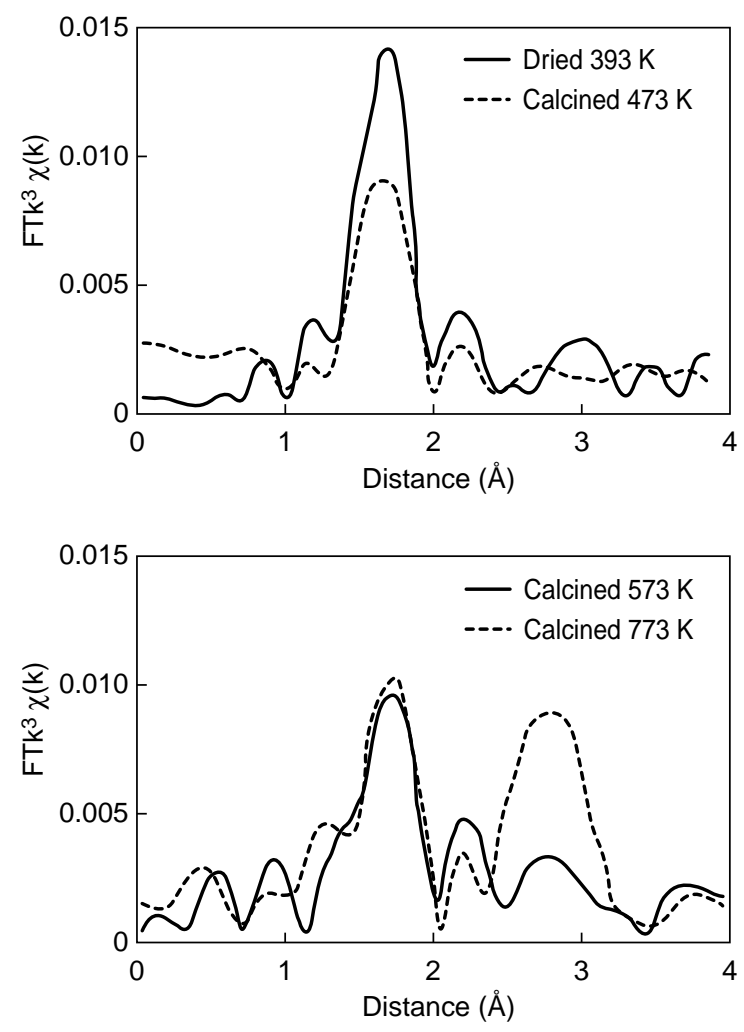

Figure 14

Fourier transforms of the EXAFS data from $\mathrm{Pt} / \mathrm{Al}_{2} \mathrm{O}_{3}$ catalysts formed from $\mathrm{Pt}$ (acac.) $)_{2}$. High temperature calcining provokes the formation of oxide particles (a peak at $2.7 \AA$ is attributed to Pt-Pt distances). 
Comparison with the case of acetylacetonate indicates the stabilising effect of chlorine during high temperature calcining.

\subsection{In situ Analysis}

However detailed the description of a catalyst, even in the activated state under hydrogen, a doubt remains as to the usefulness of analysis results in explaining catalytic activity. The catalytic act itself may modify the catalyst, or at least the site responsible for the activity. A major challenge is therefore to come as close as possible, during the analysis, to usual operating conditions of these solids. To do this we undertook the design and construction of a microreactor compatible with acquisition of EXAFS data and capable of maintaining the specimen under pressure in a reactive gas (a hydrogen/hydrocarbon mixture) at temperature [39]. To verify that the reaction conditions are realistic and to measure the activity of the catalyst, outlet gases are analysed by chromatography. For a $1 \% \mathrm{Pt} / \mathrm{Cl}-\mathrm{Al}_{2} \mathrm{O}_{3}$ catalyst in contact with $n$-heptane $\left(623 \mathrm{~K}, 3\right.$ bar, molar ratio $\mathrm{H}_{2}: n \mathrm{C}_{7}$ $=0.7: 1$ ), we showed [40] the formation of Pt-C bonds (see Fig. 15).

During $n$-heptane injection we observe, on average, one carbon neighbour per platinum atom, at a distance of $1.98 \AA$. Within the precision of the method, EXAFS results show no relaxation of Pt-Pt distances, nor do we see reconstruction of the particle during hydrocarbon adsorption. It is equally striking that the formation of Pt-C bonds is detected as soon as the catalyst comes into contact with the $n$-heptane (the acquisition time for one spectrum is $10 \mathrm{~min}$ ) and that the number of bonds stays constant during the experience $(4 \mathrm{~h})$. This result is coherent with the hypothesis that this type of catalyst is rapidly covered by a layer of "active" carbon.

We were able, by modifying the reaction conditions, to follow the desorption of the carbon deposit formed on the catalyst. The injection of $n$-heptane was stopped and the catalyst maintained under 3 bar of hydrogen at $623 \mathrm{~K}$. A slow decrease was observed in the Pt-C signal which became undetectable after $4 \mathrm{~h}$ (Fig. 15).

The carbonaceous deposit is thus adsorbed reversibly onto the metal. Again, EXAFS shows no detectable modification of the platinum environment on desorption of carbon. By reproducing the experiments "off line" we were able to measure the total quantity of $\mathrm{C}$ deposited. Carbon contents were measured on a first catalyst treated under the reaction mixture and a second after stripping in hydrogen. $2 \%$ wt of carbon was deposited in the first case (equivalent to $32 \mathrm{C}$ atoms per $\mathrm{Pt}$ atom) whilst $0.4 \%$ (equivalent to $\mathrm{C} / \mathrm{Pt}=6$ ) remained in the second. From these results we can propose that the carbon is in majority adsorbed on the support. The quantity of carbon deposited almost certainly implies a three dimensional coke structure with formation of $\mathrm{C}-\mathrm{C}$ bonds. The advantage of the use of EXAFS here is clearly to be able

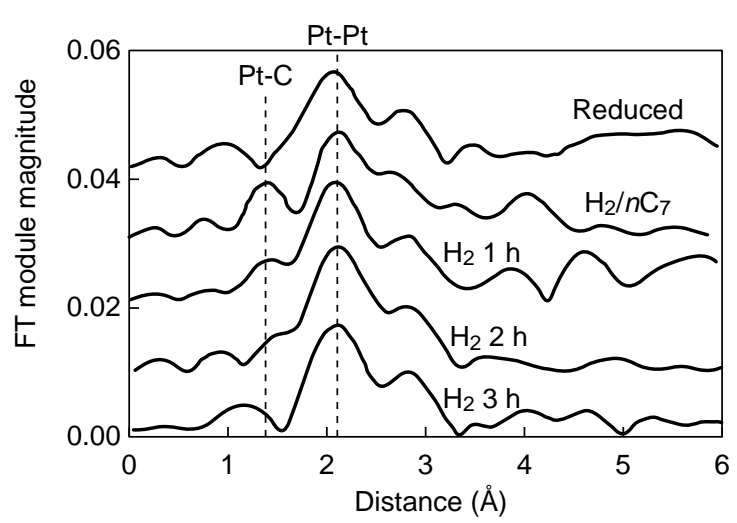

Figure 15

Fourier transforms of the EXAFS data from a $\mathrm{Pt} / \mathrm{Cl}-\mathrm{Al}_{2} \mathrm{O}_{3}$ catalyst under reaction conditions. The metallic structure, seen thorough Pt-Pt bonds, remains unchanged on contact with the hydrocarbon. A peak due to $\mathrm{Pt}-\mathrm{C}$ bonds appears under hydrocarbon and decreases when injection is stopped.

to study the absorption and desorption of carbon as seen from the catalytically active phase.

\subsection{Bimetallic Systems}

The early EXAFS studies presented above concentrated on the mono-metallic $\mathrm{Pt} / \mathrm{Al}_{2} \mathrm{O}_{3}$ system. We have already seen for microscopy the important information that can be obtained by analysis of bimetallic solids. We can illustrate how EXAFS can compliment structural analysis techniques such as microdiffraction by a carbon supported $\mathrm{Pt}-\mathrm{Zr}$ model system [41]. In this solid we showed the formation of a $\mathrm{Pt}_{3} \mathrm{Zr}$ alloy both by EXAFS at the platinum edge (evaluating global alloy formation) and by the observation in microdiffraction of a superstructure (particle by particle evaluation).

This type of study was further extended to other important reforming catalyst systems such as $\mathrm{Pt}-\mathrm{Sn} / \mathrm{Al}_{2} \mathrm{O}_{3}$ [42-44] and $\mathrm{Pt}-\mathrm{Re} / \mathrm{Al}_{2} \mathrm{O}_{3}[45,46]$. We will deal in detail here only with the second case.

Addition of Re to Pt- $\mathrm{Al}_{2} \mathrm{O}_{3}$ catalysts is known to improve performance in terms of stability and selectivity. Several explanations may be proposed such as the capacity of Re to intercept and destroy coke precursors. Due to the small particle size, little information is available on the state of the metals in the active catalyst and à fortiori during the reaction. EXAFS provides us with part of the solution.

$\mathrm{Pt}$ and Re a close in atomic number. As a result it is impossible to distinguish them as neighbours in EXAFS analysis. We can however analyse the environment of these two elements independently and almost simultaneously.

We studied two systems: $1 \% \mathrm{Pt}$ and $1 \% \mathrm{Pt}-1 \% \operatorname{Re}[47,48]$ deposited on chlorinated alumina by impregnation from solutions of $\mathrm{H}_{2} \mathrm{PtCl}_{6}$ and $\mathrm{NH}_{4} \mathrm{ReO}_{4}$ (both systems had a final chlorine loading of $1.2 \% \mathrm{wt}$ ). Samples were dried at $393 \mathrm{~K}$ 
and calcined at $773 \mathrm{~K}$ before reduction, carried out at $733 \mathrm{~K}$ under 3 bar of $\mathrm{H}_{2}$ for $2 \mathrm{~h}$. We then introduced $n$-heptane for $4 \mathrm{~h}$ at a molar ratio of $\mathrm{H}_{2}$ /hydrocarbon of 0.9 and a total pressure of 3 bar. These conditions favoured rapid deactivation of the catalysts, so that we could study the process during a single EXAFS experiment. Catalytic activity was followed by gas phase chromatography of the products. For the bimetallic system, after reaction at $733 \mathrm{~K}$, we had to decrease the temperature to $573 \mathrm{~K}$ to accelerate the deactivation phenomenon which was followed for a further $2 \mathrm{~h}$.

In the reduced monometallic system the Pt-Pt coordination number was 5. Under $\mathrm{H}_{2}+$ hydrocarbon mixture the presence of Pt-C bonds $\left(\mathrm{N}_{\mathrm{Pt}-\mathrm{C}}=1.2\right.$ at $1.94 \AA$ ) was confirmed. As we have seen above, the formation of Pt-C bonds does not affect the structure of the platinum particles. Whilst the activity changes with time, showing deactivation of the catalyst, the environment of platinum remains unchanged.

For the $\mathrm{L}_{\mathrm{III}}$ edge of $\mathrm{Pt}$ in the bimetallic system, a lower $\mathrm{Pt}$ coordination number ( $\mathrm{Pt}$ to $\mathrm{Pt}$ and/or $\mathrm{Re}$ ) of 3.6 is observed. Compared to 5 for the mono-metallic, this indicates a smaller particle size in the bimetallic catalyst, in agreement with the known increase in platinum dispersion on addition of Re. The state of Pt during the reaction is also modified. Here, EXAFS shows an absence of Pt-C bonds at a temperature of $733 \mathrm{~K}$. The formation Pt-C bonds ( 2 at $2.09 \AA$ ) was only observed on reducing the reaction temperature to $573 \mathrm{~K}$ (Fig. 16). Differences in the number and distance of Pt-C bonds may indicate a qualitative difference in the carbon deposit compared with the monometallic case. A marked decrease in $n$-heptane conversion for the bimetallic catalyst is observed on reducing the temperature to $573 \mathrm{~K}$.

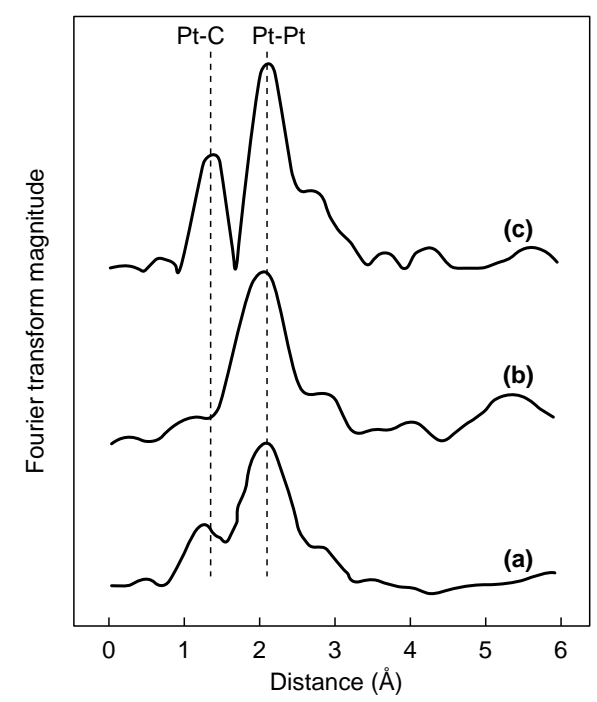

Figure 16

Fourier transforms of the platinum edge EXAFS of catalysts under reaction conditions. (a): $\mathrm{Pt} / \mathrm{Cl}-\mathrm{Al}_{2} \mathrm{O}_{3}$ at $773 \mathrm{~K}$; (b): Pt$\mathrm{Re} / \mathrm{Cl}-\mathrm{Al}_{2} \mathrm{O}_{3}$ at $773 \mathrm{~K}$; Pt-Re/Cl- $\mathrm{Al}_{2} \mathrm{O}_{3}$ at $573 \mathrm{~K}$. Pt-C bonds are observed only in (a) and (c).
Thus, at high temperature, Pt-C bonds are not detected in the Pt-Re system, but chromatographic analysis of the products show that the catalyst is active under these conditions. An interpretation of these structural differences in active bimetallic catalysts compared to monometallic systems may be proposed taking into account that Re-C bonds are not observed under conditions used here. The activity of $\mathrm{Re}$ in hydrogenation is well known and may explain, by rapid conversion of coke precursors, the lack of observation of $\mathrm{Re}-\mathrm{C}$ bonds. Interception by rhenium of coke precursors could therefore also explain the absence of Pt-C bonds in the bimetallic system.

Despite the absence of visible bonds between the rhenium and hydrocarbons, we observe strong modification of this element's environment during the reaction. After reduction under $\mathrm{H}_{2}$ at $733 \mathrm{~K}$ the average coordination sphere of rhenium contains 1.4 oxygen atoms. The number of Re-M $(\mathrm{M}=\mathrm{Pt}$ or $\mathrm{Re})$ bonds detected is low $\left(\mathrm{N}_{\mathrm{Re}-\mathrm{M}}=2\right)$. Rhenium appears to interact strongly with the support oxide, forming a well dispersed phase which is difficult to reduce. During the reaction under hydrocarbon rhenium looses oxygen neighbours and the number of Re-M bonds increases $\left(\mathrm{N}_{\mathrm{Re}-\mathrm{M}}=4\right.$ at $773 \mathrm{~K} ; 6.5$ at $573 \mathrm{~K}$ ). EXAFS shows that rhenium is progressively reduced and participates in the formation of metallic particles.

\subsection{The Interaction with Sulphur}

Following the encouraging results obtained for PtRe/alumina catalysts under reaction mixtures, the EXAFS study was extended to the behaviour of the system during another step in the catalyst's life cycle: sulphidation [49, 50].

Because of the high hydrogenating power of $\mathrm{Re}$, controlled sulphidation is an important step in the activation of bimetallic Pt-Re catalysts. Sulphur is on the contrary considered a poison for monometallic $\mathrm{Pt} / \mathrm{Al}_{2} \mathrm{O}_{3}$ catalysts. Our aim was to propose a structural basis for this difference in response to sulphur of the two systems. The characteristics of the solids and the conditions of activation are as described above. After reduction under hydrogen, sulphidation was carried out at $723 \mathrm{~K}$ in a $1 \% \mathrm{H}_{2} \mathrm{~S}$ in hydrogen mixture. This was followed by a second reduction (under pure hydrogen) in order to observe the effect of possible sulphur desorption.

Results obtained after the first reduction confirm those described above. Particularly noteworthy is the lower coordination number for $\mathrm{Pt}$ in the bimetallic catalyst and the presence of oxygen in the coordination sphere of $\mathrm{Re}$ indicating that the reduction of this element is not complete.

After sulphidation, the environment of platinum in the monometallic catalyst consists entirely of sulphur. The metallic particles have been completely destroyed by the treatment. An average of 2.8 sulphur atoms are detected at a distance of $2.32 \AA$. The metallic particles are in part restored by the second treatment under hydrogen (however, the Pt-Pt 
coordination number rises only to 1.5 whilst the Pt-S coordination number remains unchanged).

The intrusion of sulphur in the coordination sphere of both metals is observed for the bimetallic solid during sulphidation (for Pt; $\mathrm{N}_{\mathrm{Pt}-\mathrm{S}}=2$ at $2.32 \AA$, for Re; $\mathrm{N}_{\mathrm{Re}-\mathrm{S}}$ $=2.4$ at $2.36 \AA$ ). However, the metallic particles are seen to be left intact, as indicated by the Pt-M and Re-M coordination numbers not being significantly modified. The second reduction does not change the environment of Re but the Pt-S coordination number is reduced from 2 to 1 .

These results, represented schematically in Figure 17, clearly show the destruction of the metallic structure in presence of sulphur only for the $\mathrm{Pt} / \mathrm{Al}_{2} \mathrm{O}_{3}$ catalyst. Analysis of the bimetallic case allows constraints to be put on models of the role played by the second metal in preserving catalytic properties in presence of sulphur. Our results show the formation of both Re-S and Pt-S bonds. They also provide indication, through the changes after the second reduction, that the Re-S bond is more stable than the Pt-S bond.

The examples shown here illustrate clearly the contribution of EXAFS to the development of structural models of the behaviour of small particles under reactive atmospheres. The technique provides independent information from each element in a bimetallic catalyst allowing a coherent story to be told. We must not however forget that EXAFS is a one dimensional technique, giving only the radial distribution around the central atom. This means that the construction of 3D models such as those proposed in Figure 17 can only be a visualisation aide and must not be taken literally. In order to locate atoms inside a three dimensional structure, as we wish
After calcination

$\mathrm{N}(\mathrm{PtO})=6$

First reduction under hydrogen

$\mathrm{N}(\mathrm{PtO})=0.4$

$\mathrm{R}(\mathrm{PtO})=2.01 \AA$

$\mathrm{N}(\mathrm{PtPt})=4.5$

$\mathrm{R}(\mathrm{PtPt})=2.72 \AA$

Sulphidation under $1 \% \mathrm{H}_{2} \mathrm{~S} / \mathrm{H}_{2}$

$\mathrm{N}(\mathrm{PtS})=2.8$

$\mathrm{R}(\mathrm{PtS})=2.32 \AA$
$\mathrm{R}(\mathrm{PtO})=2.04 \AA$

\section{$1 \%$ platinum/alumina}
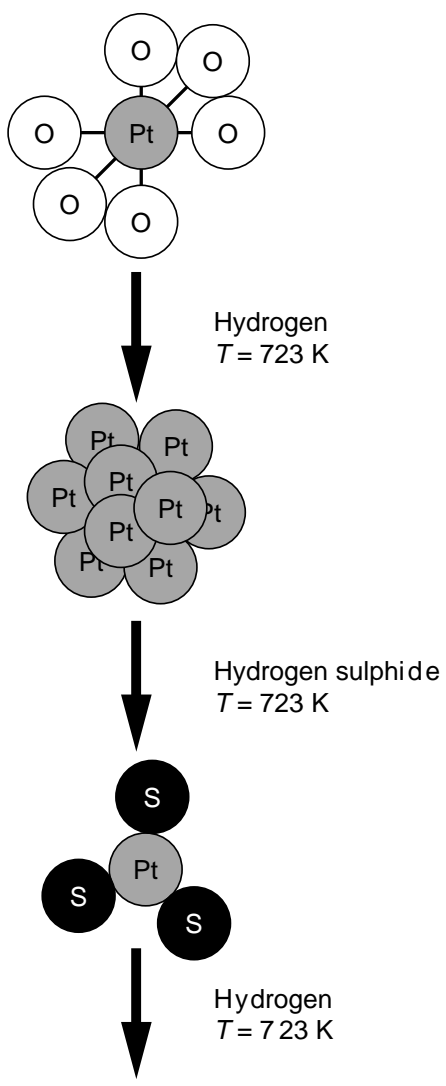

Second reduction under hydrogen

$\mathrm{N}(\mathrm{PtS})=2.8$

$R(P t S)=2.30 \AA$

$\mathrm{N}(\mathrm{PtPt})=1.5$

$\mathrm{R}(\mathrm{PtPt})=2.71 \AA$

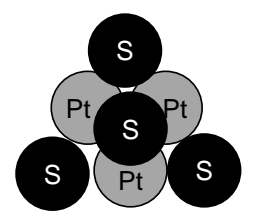

Figure 17(a)

Representation of the modifications to a $\mathrm{Pt} / \mathrm{Al}_{2} \mathrm{O}_{3}$ catalyst during reduction and under $\mathrm{H}_{2} \mathrm{~S}$. The metallic particles are destroyed by the adsorption of sulphur. 


\section{1\% Pt 1\% Re/alumina}

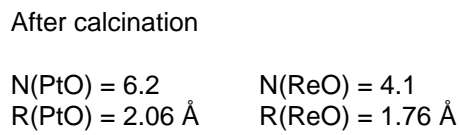

Sulphidation under $1 \% \mathrm{H}_{2} \mathrm{~S} / \mathrm{H}_{2}$

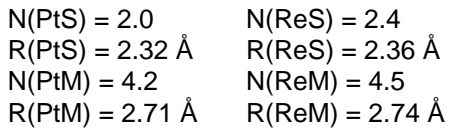

Second reduction under hydrogen

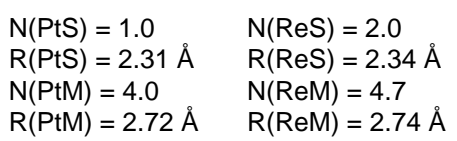

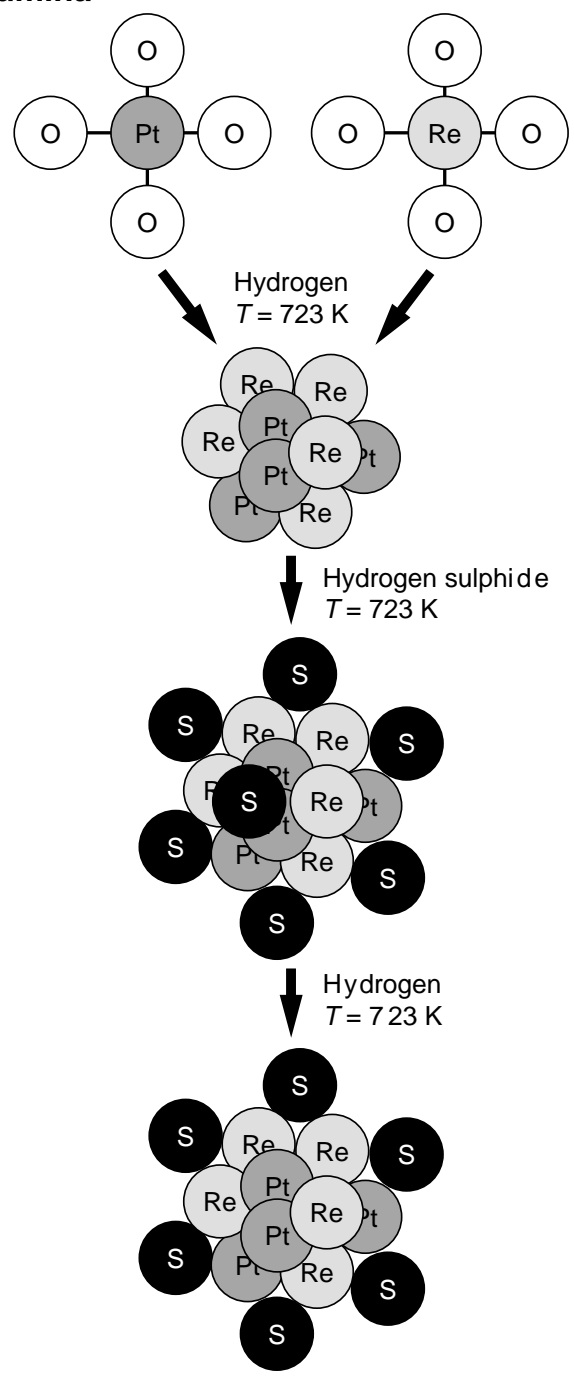

Representation of the modifications to a Pt-Re $/ \mathrm{Al}_{2} \mathrm{O}_{3}$ catalyst during reduction and under $\mathrm{H}_{2} \mathrm{~S}$. Despite a high metal-sulphur coordination the metallic structure remains intact.

to do in many cases of well crystallised systems such as zeolites, we need access to information of a different nature. This is furnished in particular by X-ray diffraction, which we will consider in the next section.

\section{ZEO LTE BASED SOLIDS}

An important part of our research into microporous solids has been concerned with following the structural evolution of $\mathrm{Y}$ zeolite following different stabilisation treatments involving dealumination. Having seen the advantages and limits of analytical microscopy, we considered here the combination, with TEM, of global techniques, and in particular XRD, for structural analysis of these solids.

\subsection{Hydrothermal Treatment}

Y zeolites are synthesised with low $\mathrm{Si} / \mathrm{Al}$ ratios, of the order of 2.5. For catalytic applications it is necessary to increase this ratio in order to confer thermal stability to the solid. High temperature treatment under water vapour (known as steaming) is the most common method used to adjust the $\mathrm{Si} / \mathrm{Al}$ ratio of the zeolite network. The aluminium atoms extracted from the network by this treatment (extraframework aluminium or EFAL) are directly replaced by silicon atoms coming from other network sites. In order to preserve the microporous qualities of the solid, it is necessary to extract these EFAL. At the end of this series of treatments, the solids present a certain amount of mesoporosity. 
In order to optimise the process, it appeared important to be able to follow quantitatively the EFAL, so as to be able to map out, in as detailed a way as possible, the distribution of species generated during dealumination. The mobility of aluminium atoms being probably strongly influenced by the temperature, we first established, as a function of steaming temperature, the framework dealumination and the formation of EFAL [51].

The starting materiel for this study is a $\mathrm{Y}$ zeolite of $\mathrm{Si} / \mathrm{Al}$ ratio 2.7 in the $\mathrm{NH}_{4} \mathrm{Y}$ form. Specimens were obtained by steaming at temperatures of $873 \mathrm{~K}, 1003 \mathrm{~K}, 1073 \mathrm{~K}$.

Several techniques are capable of detecting, and in certain cases quantifying, the presence of EFAL species, in particular XRD and aluminium NMR. X-ray diffraction analysis using the Rietveld technique shows the presence of three types of extra-framework atoms within the network symmetry. These three positions are located on the ternary axis of the sodalite cage, one at the cage centre, the others between this position and the window of the hexagonal prism. Based on interatomic distances, we proposed that two positions, at the cage centre and close to the hexagonal prism, are occupied by EFAL. The site between these two is attributed to oxygen atoms.

The evolution of the unit cell contents of the zeolite can be followed using X-ray fluorescence to obtain the global Si/Al ratio and X-ray diffraction (measuring the unit cell parameter) to obtain the network $\mathrm{Si} / \mathrm{Al}$ ratio. One unit cell of the zeolite contains $192 \mathrm{~T}$ atoms ( $\mathrm{Si}$ or $\mathrm{Al}$ ). It is thus possible to calculate the total number of aluminium atoms per unit cell and the number of these $\mathrm{Al}$ atoms contained in the framework. The difference between these values gives the average number of EFAL per unit cell. These results are compared in Table 1 to the number of extra-framework species detected par XRD (Rietveld).

TABLE 1

Evolution of different types of aluminium after steaming as a function of temperature

\begin{tabular}{|c|c|c|c|c|}
\hline & $873 \mathrm{~K}$ & $1003 \mathrm{~K}$ & $1073 \mathrm{~K}$ \\
\hline \multicolumn{2}{|c|}{ Crystallinity (\%) } & 84 & 89 & 91 \\
\hline \multicolumn{2}{|c|}{ Global Si/Al $( \pm 0.1)$} & 2.7 & 2.7 & 2.6 \\
\hline \multicolumn{2}{|c|}{ Framework Si/Al } & $11 \pm 1$ & $15 \pm 2$ & $50 \pm 10$ \\
\hline & Total $( \pm 1)$ & 52 & 52 & 53 \\
\hline \multirow[t]{2}{*}{$\mathrm{Al}$ per unit cell } & Framework $( \pm 2)$ & 16 & 12 & 4 \\
\hline & EFAL $( \pm 3)$ & 36 & 40 & 49 \\
\hline \multicolumn{2}{|c|}{ EFAL close to the hexagonal window } & 6 & 1 & 0 \\
\hline \multicolumn{2}{|c|}{ EFAL at the cage centre } & 2 & 3 & 0 \\
\hline
\end{tabular}

Clearly, a large fraction of the EFAL does not have the framework symmetry. In addition, with increasing temperature, a decrease of the number of EFAL detected by XRD is observed, reaching zero for high steaming temperature, whereas the total number of EFAL increases.

Other global techniques show the same, at first sight surprising, effect. NMR spectroscopy of ${ }^{27} \mathrm{Al}$ with magic angle rotation shows three types of aluminium in the steamed solids. A peak at $60 \mathrm{ppm}$ chemical shift (with respect to $\mathrm{Al}\left(\mathrm{H}_{2} \mathrm{O}\right)_{6}{ }^{3+}$ taken as reference) is due to fourfold coordinated aluminium (AlIV). The aluminium atoms of the framework in tetrahedral coordination contribute to this signal as may some EFAL. On steaming, the appearance of aluminium in octahedral coordination, AlVI (0 ppm) and of a species giving rise to a peak at $30 \mathrm{ppm}$, often denoted AlV, are observed. Quantification of NMR spectra of a quadrupolar nucleus such as ${ }^{27} \mathrm{Al}$ is however delicate. This is illustrated by an overall decrease in intensity, in particular for the extraframework species at $0 \mathrm{ppm}$, when the number of EFAL increases.

Infrared spectroscopy shows a similar evolution for the hydroxyl groups linked to the EFAL. Although a strong band at $3600 \mathrm{~cm}^{-1}$ (attributed to extra-framework $\mathrm{Al}-\mathrm{OH}$ groups) appears after the treatment at $873 \mathrm{~K}$, its intensity decreases for steaming at $1003 \mathrm{~K}$ and the band disappears after treatment at $1073 \mathrm{~K}$.

Thus for three global techniques, XRD (Rietveld), NMR and IR spectroscopy, the signals which could be related to extra-framework species decrease as the number of these species increases. The reorganisation taking place during stabilisation of Y zeolite was clarified by a TEM study. By observing thin sections we were able to directly observe the modifications induced by steaming. Amorphous regions, of high density relative to the zeolite, were observed in steamed solids. These amorphous regions are of two forms, spherical particles ( 3 to $10 \mathrm{~nm}$ in diameter) in the grain interior and an external shell of the order of $10 \mathrm{~nm}$ in thickness. Extraction of extra-framework aluminium leaves mesopores in place of the first type of region (Fig. 18).

We are led to suggest that these zones are created by the mobility, during steaming, of the aluminium extracted from the network. Zones of amorphous alumina are formed either in mesopores created by local destruction of the structure, or at the surface of the grains. The surface $\mathrm{Si} / \mathrm{Al}$ ratio determined by X-ray photoelectron spectroscopy (XPS) [52] supports this hypothesis.

EFAL condensation to an amorphous phase is responsible for the phenomena observed using global techniques. The formation of cationic species at low temperature and polymeric dehydroxylated species at high temperature is consistent with the observed evolution of the hydroxyl band in IR attributed to extra-framework species. The quantity of extra-framework species increases with steaming temperature but their condensation to form amorphous zones prohibits their visualisation by X-ray diffraction and by NMR. 


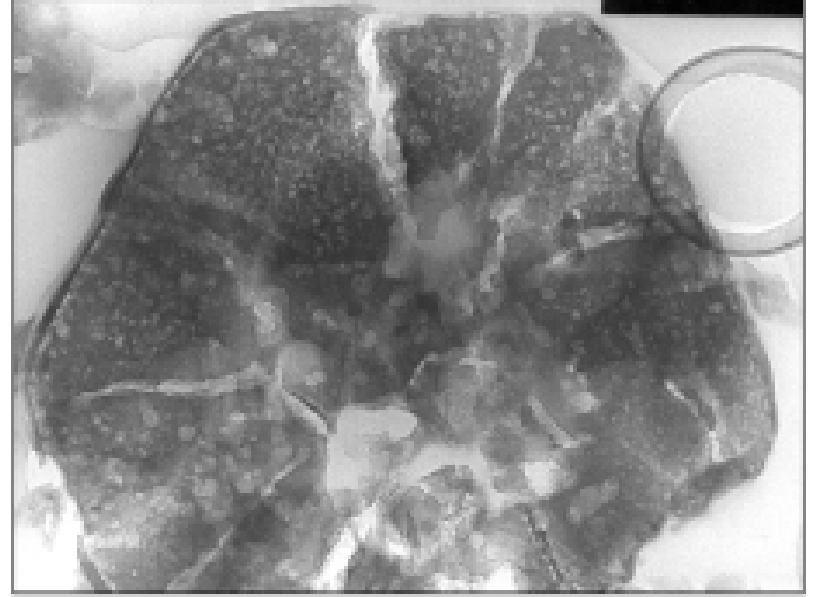

Figure 18

TEM image of a stabilised zeolite. An external shell of amorphous alumina and internal mesopores created during dealumination are observed (imaged area is $1 \mu^{2}$ in size).

These studies thus suggest the existence of several types of EFAL. The distribution of EFAL amongst these different forms could have an important effect on the activity of zeolite containing catalysts. It is thus important to test the limits of quantification of the available techniques in order to reach a detailed description of this distribution. TEM confirms that part of the EFAL are condensed and gives textural indications of their location. Quantification is however not possible using this technique alone. We have thus combined results obtained from several analysis techniques following different leaching treatments of a steamed solid.

\subsection{Q uantification of Extra-Framew ork Species}

Studies reported in the literature describe the use of various agents for the elimination of EFAL formed during steaming, such as nitric acid, ammonium hexafluorosilicate (AHFS) and ethylene diamine tetra-acetique acid (EDTA). Differences in the nature of these agents suggest that they may act preferentially on one or another of the EFAL species. We therefore compared, in a detailed characterisation study, the action of these agents on a $\mathrm{NH}_{4} \mathrm{Y}$ zeolite steamed at $923 \mathrm{~K}$.

The starting Y zeolite, with a $\mathrm{Si} / \mathrm{Al}$ ratio of 2.7 , contained $51 \mathrm{Al}$ atoms par unit cell. In the steamed solid, with the same global $\mathrm{Si} / \mathrm{Al}$ ratio, $17 \mathrm{Al}$ atoms par unit cell remain in the framework (framework $\mathrm{Si} / \mathrm{Al}$ ratio $=11$ ). This solid thus contains 34 EFAL per unit cell.

Figure 19 shows the evolution of the number of EFAL as a function of the strength of the treatment (by nitric acid, EDTA or AFHS) of aluminium extraction. Here the strength is expressed as moles of the dealuminating agent $\left(\mathrm{HNO}_{3}\right.$, $\mathrm{NH}_{4} \mathrm{SiF}_{6}, \mathrm{H}_{2} \mathrm{Na}_{2}$ EDTA) per mole of aluminium in the steamed solid.

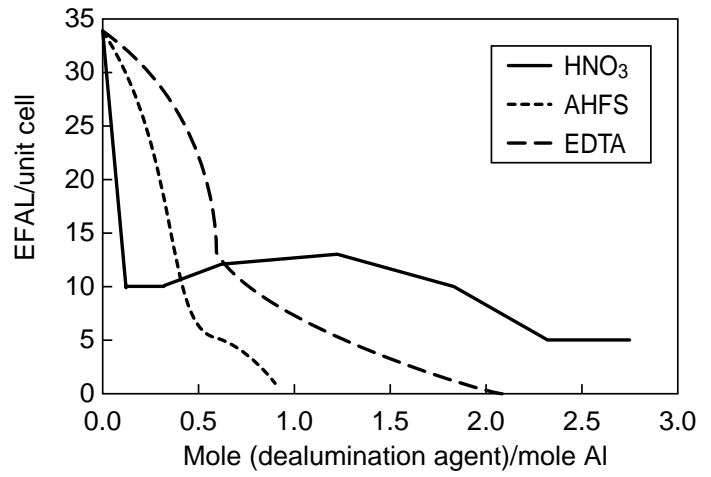

Figure 19

Evolution of the number of EFAL per unit cell in a $\mathrm{Y}$ zeolite with strength of treatment by $\mathrm{HNO}_{3}$, AHFS and EDTA. The steamed solid is represented at the origin.

We first note that extraction of part of the EFAL by nitric acid is achieved by very low strengths. The number of EFAL per unit cell falls from 34 to 11 at a strength of 0.1 . The fact that the number of EFAL then remains constant over a large range indicates however that the remaining EFAL are at least as resistant to acid attack as the $\mathrm{Al}$ atoms of the framework (the framework is destroyed for very strong acid treatments).

The action of AHFS is on the contrary progressive. In the range of strengths from 0.13 to $0.42,26$ EFAL per unit cell (75\% of the EFAL present after steaming) are extracted. Extraction by AHFS of the remaining EFAL seems less easy, extraction of all EFAL requiring a strength of 1 . The decrease in EFAL concentration due to EDTA shows a similar behaviour to that observed for AHFS. However, EDTA is only half as efficient (elimination of 26 EFAL requires a strength of $0.9 \mathrm{EDTA} / \mathrm{Al})$.

$\mathrm{X}$-ray diffraction shows that steaming provokes a decrease in crystallinity (defined by comparing the surface of diffraction peaks due to the zeolite with that of the starting material). The relative crystallinity of the steamed solid is $83 \%$ that of the starting solid. At the same time, the specific surface area falls from 930 to $734 \mathrm{~m}^{2} / \mathrm{g}$. These observations confirm the formation of amorphous material. After nitric acid treatment crystallinity recovers to $95 \%$, whilst specific surface area increases to close to $900 \mathrm{~m}^{2} / \mathrm{g}$. EFAL extraction by nitric acid is thus accompanied by an increase in crystallinity, due to elimination of amorphous material "blocking" the porosity. The variations in cristallinity and specific surface area during leaching by EDTA are similar to those observed with nitric acid. This is not the case for AHFS. The loss in crystallinity is not recovered for treatment strengths below 0.64. Specific surface area stays practically constant whatever the treatment strength for AHFS.

Although it is probable that the different agents affect different EFAL species, we cannot simply say that nitric acid and EDTA remove polycondensed (amorphous) EFAL 
whereas these types of EFAL are left by AHFS. We shall see that the species resistant to AHFS are identifiable by XRD and therefore have the framework symmetry of the zeolite. It is rather strongly probable (and suggested by XPS results) that AHFS treatment results in the replacement of aluminium by silicon in the amorphous phase [53].

Analysis of ${ }^{27} \mathrm{Al}$ NMR spectra provide (Fig. 20) qualitative indicators of the evolution of the EFAL. The spectrum from the steamed solid shows, as before, three types of aluminium: AlIV at least some of which are framework $\mathrm{Al}$, AlV and AlVI. AHFS treatment results in elimination of both AlV and AlVI. The effect of acid treatment is elimination of AlV and a part of the AlVI, those left, as shown by a sharp peak at $0 \mathrm{ppm}$, being cationic species similar to $\mathrm{Al}\left(\mathrm{H}_{2} \mathrm{O}\right)_{6}{ }^{3+}$.

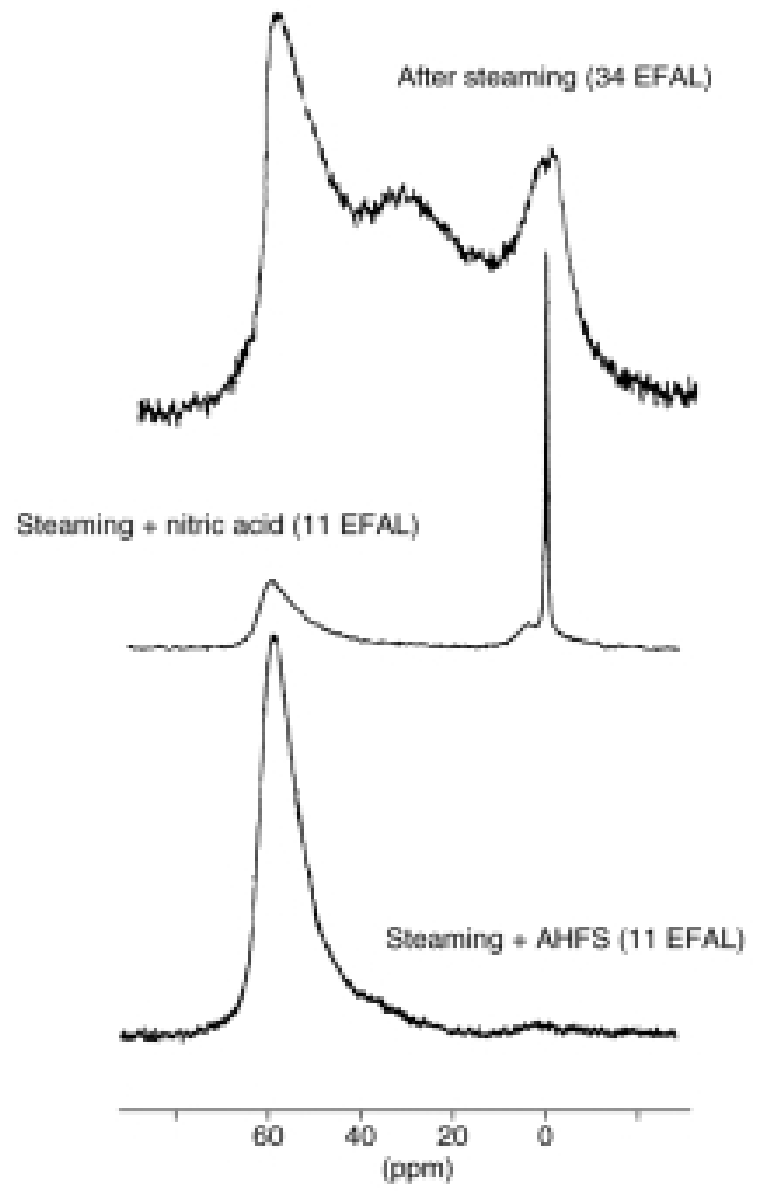

Figure 20

${ }^{27} \mathrm{Al}$ NMR spectra of steamed and dealuminated zeolites showing the presence of AlIV (60 ppm), AlV (30 ppm) and AlVI (0 ppm).

Rietveld analysis of the XRD pattern obtained for the steamed solid confirms results of the preceding study.
Six aluminium atoms per unit cell close to the hexagonal window and $2.5 \mathrm{Al}$ near the sodalite cage centre are detected. 4.5 oxygen atoms per unit cell are associated to the latter, leading us to suppose that the species at the cage centre are of the form $\mathrm{Al}(\mathrm{OH})_{2}{ }^{+}$. The tetrahedral symmetry of the site and the oxygen coordination number of the aluminium imply that these species differ from the AlV and AlVI seen by NMR.

Nitric acid leaching removes the species located close to the hexagonal window, leaving intact the species at the sodalite cage centre (2.5 EFAL per unit cell). AHFS has the reverse effect. Here only the species at the sodalite cage centre are removed. Quantitatively, for a solid treated by AHFS, so as to leave only 7 EFAL per unit cell, we still identify 6 aluminium atoms per unit cell close to the hexagonal window. It therefore seems that these species, eliminated by nitric acid, are the most resistant to AHFS. It is noteworthy that this solid presents a single NMR peak, attributed to AlIV atoms. The symmetry of the site detected by XRD (Reitveld) close to the hexagonal window and the distances between these EFAL and three oxygen atoms of the framework forming the window are indeed coherent with a tetrahedral environment (Fig. 21).

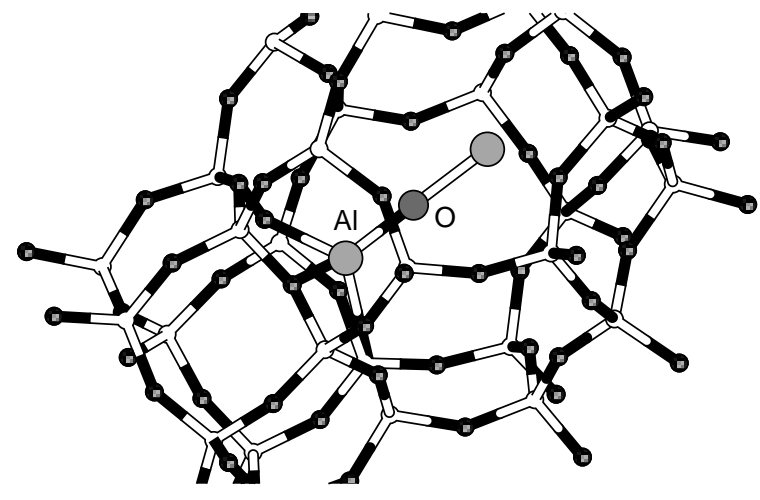

Figure 21

Representation of a fragment of the structure of $\mathrm{Y}$ zeolite showing the position of an EFAL close to the hexagonal window. Tetrahedral coordination is assured by three oxygen atoms of the framework and one extra-framework oxygen atom.

Of the 34 EFAL atoms per unit cell generated by steaming, about 6 are thus identified as being AlIV attached to the framework. A further 11 (of which 2 are at the centre of the sodalite cage) are resistant to nitric acid attack, and are most likely in the form of isolated cations, such as $\mathrm{Al}\left(\mathrm{H}_{2} \mathrm{O}\right)_{6}{ }^{3+}$ and $\mathrm{Al}(\mathrm{OH})_{2}{ }^{+}$. This would imply that polycondensed EFAL, the amorphous phase visible in TEM, constitutes only about half of the total EFAL. 
We still do not have, at the present stage, a complete vision of the distribution of EFAL among the various forms. It is however clear that this type of multitechnique study allows us to approch this difficult problem of quantification of extra-framework species in zeolites. The results clearly show that the nature of aluminium extra-framework atoms differs depending on the leaching agent. Solids with different controlled types of EFAL were tested for their catalytic activity using $n$-decane as a reactant. For quantities of EFAL lower than 10 per unit cell, no influence of the nature and number of EFAL on the hydrocracking or isomerisation activity was observed [54]. This lack of influence may be explained on the one hand by the low surface developed by condensed EFAL in amorphous form, and on the other by the inaccessibility of EFAL dispersed in cationic form. The latter are seen as isolated species contained in cages of small diameter. There remains however the possibility that, during the reaction, the EFAL are displaced to different sites. Under reaction conditions there may be a homogenisation of the solids, leading to an identical catalytic activity for initially different solids.

The above example shows that X-ray diffraction can give us information on the quantity and the position of atoms belonging to the crystallographic structure of the zeolite. For solids containing aluminium in a variety of forms differing in long range ordering, in short range coordination, and in interaction with the framework, it is however not possible to determine, using a single technique, the distribution of the various species. An approach to quantification has been possible by combining diffraction with nuclear magnetic resonance, a technique well adapted to the study of the local environment of aluminium. It is clear that application of a range of techniques, with sensitivity to different forms of structure, is necessary to understand a complex catalytic system.

This study was not able to respond to the question of a possible modification to the environment of aluminium during the catalytic reaction. Given the useful results obtained using in situ EXAFS for the study of highly dispersed metallic systems, the development of in-situ X-ray diffraction was clearly a logical extension to this theme of research in the characterisation of catalysts. The following section presents recent results obtained using this technique.

\section{POORLY CRYSTAWISED SO LIDS}

We have seen in the examples of reforming catalysts and in the localisation of extra-framework species in $\mathrm{Y}$ zeolite the strengths of EXAFS and XRD in, respectively, the study of highly divided and well crystallised systems. In the case of poorly crystallised solids such as mixed oxides and FischerTropsch catalysts, our research on which is considered in this secion, greater insight is obtained by using both techniques together. These two types of solids, although consisting in a first approximation of particles tens of nanometers in size, present atomic scale defects which influence their catalytic properties. A multitechnique approach is needed to obtain as complete as possible a description of the solids and of the modifications induced by reactions.

\subsection{Short and Long Range O rder}

Hydrotalcites, which are precursors of mixed oxide systems, have a lamellar structure containing both divalent and trivalent cations, and can present a marked structural disorder.

In order to describe in detail this type of solid, we applied a special kind of analysis to X-ray diffraction patterns of hydrotalcites containing $\mathrm{Mg}$ and $\mathrm{Ga}$ cations [55] in order to extract the electron radial distribution function (known as DER for distribution électronique radiale). This technique, coupled with the use of synchrotron radiation, provides information on the environment of gallium complementary to that of EXAFS. Whereas EXAFS can reveal the type of neighbours of a given atom, DER analysis gives precise details of the geometry of the environment, over a larger distance. In Figure 22 we show the partial DER around gallium in a Ga-Mg hydrotalcite specimen. The results are compared with those derived from a simulation using the $\mathrm{Ga}-\mathrm{O}$ and $\mathrm{Ga}-(\mathrm{Mg}, \mathrm{Ga})$ distances deduced from the XRD unit cell parameters. The differences between experimental and model data as well as the EXAFS results on the same system, indicate that the Ga-O distance $(1.95 \AA)$ is shorter than the average cation-oxygen distance $(2.05 \AA)$ whereas the Ga-cation distances are stretched by a corresponding amount, $0.1 \AA$, compared to the average cation-cation distance. These results imply a distortion of the unit cell around the gallium atoms.

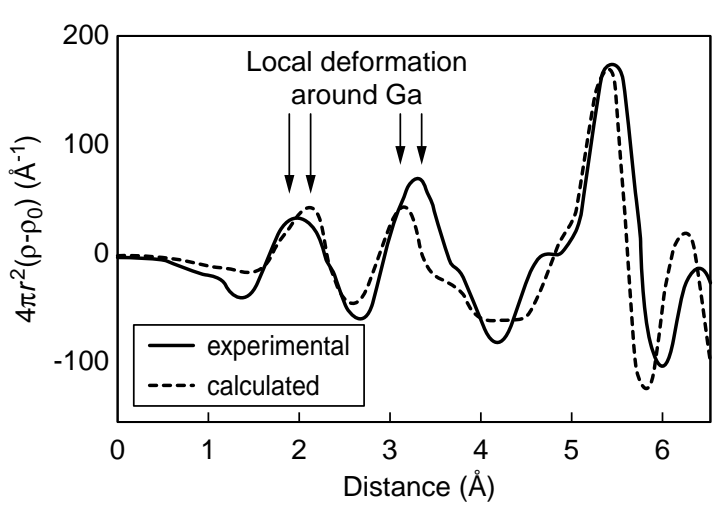

Figure 22

Comparison of the electron radial distribution around $\mathrm{Ga}$ in a hydrotalcite and in a simulation using the average interatomic distances. A compression of the first distance ( $\mathrm{Ga}-\mathrm{O}$ near $2 \AA$ ) and an expansion of the second distance (Ga-cation near $3 \AA$ ) is visible. 
In a follow-up to this study [56], the evolution of the gallium environment during the decomposition of these solids to form mixed oxides was followed by EXAFS and DER. A commercial reaction cell was used, allowing heating to $873 \mathrm{~K}$ whilst acquiring XRD data. Figure 23 shows evidence of the diffusion of gallium out of the octahedral sites at $473 \mathrm{~K}$, the temperature at which the hydrotalcite structure is dehydroxylated, although the decomposition to a mixed oxide is not complete until $773 \mathrm{~K}$.

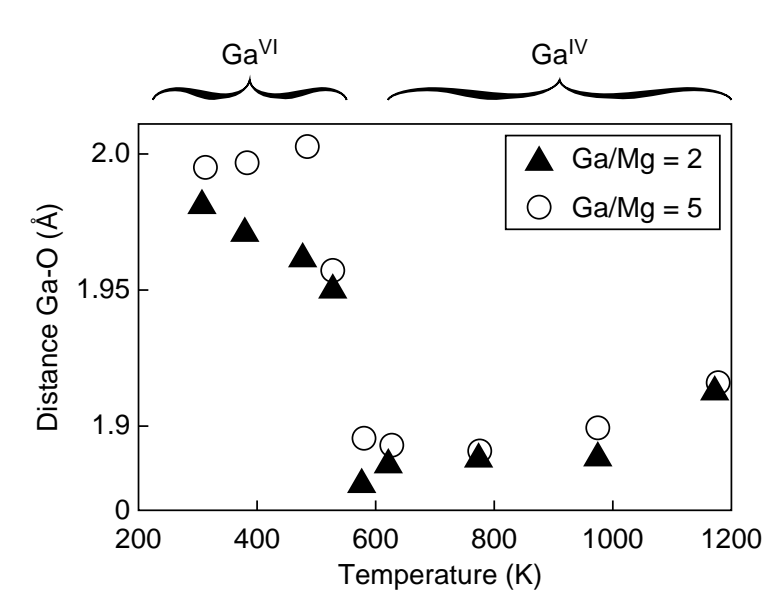

Figure 23

Following the Ga-O distance as a function of temperature to detect the transition from octahedral sites $(\mathrm{Ga}-\mathrm{O}=1.99 \AA)$ to tetrahedral sites $(\mathrm{Ga}-\mathrm{O}=1.89 \AA)$.

After decomposition at $773 \mathrm{~K}$, EXAFS shows a local environment of gallium coherent with its presence in the tetrahedral sites of a spinel structure. Despite this, the Ga-Ga distances expected from an ordered structure are absent from the radial electron distribution function. This led us to propose the existence of disorder in the cation distribution in this material, which may be linked to the high specific surface area of the mixed oxides formed by the decomposition.

Here, as in the case of EXAFS, the possibility of obtaining $\mathrm{XRD} / \mathrm{DER}$ data in reaction cells transparent to X-rays opens the way to detailed reactivity studies of these solids.

\subsection{The Metal - Support Interaction}

Our last example will focus on the study of cobalt catalysts on oxide supports, candidates for a new generation of catalysts for the Fischer-Tropsch synthesis [57]. This study required modifications to the in-situ XRD reaction cell to allow study of these solids under conditions close to those of the Fischer-Tropsch synthesis and to allow analysis of the gaseous and liquid products.

In the oxide precursor, XRD identifies the presence of cobalt oxide particles with the $\mathrm{Co}_{3} \mathrm{O}_{4}$ structure. Measurement of the width of the diffraction lines leads to an estimation of their size, up to several tens of nanometers depending on Co loading.

The reduction of cobalt oxide was followed in situ by $\mathrm{XRD}$. This showed the reduction to take place in two steps, $\mathrm{Co}_{3} \mathrm{O}_{4} \rightarrow \mathrm{CoO} \rightarrow \mathrm{Co}$. The temperature of the first transition is independent of the particle size. The final reduction to metallic cobalt appears however more difficult for catalysts containing particles in the smaller size range (Fig. 24).

For $\mathrm{Co}_{3} \mathrm{O}_{4}$ supported on silica, XRD during reduction of the particles shows (Fig. 25) the transition $\mathrm{Co}_{3} \mathrm{O}_{4} \rightarrow \mathrm{CoO}$ $\rightarrow \mathrm{Co}$ and the formation of a complex metallic particle structure, presenting both the hexagonal and cubic forms of cobalt.

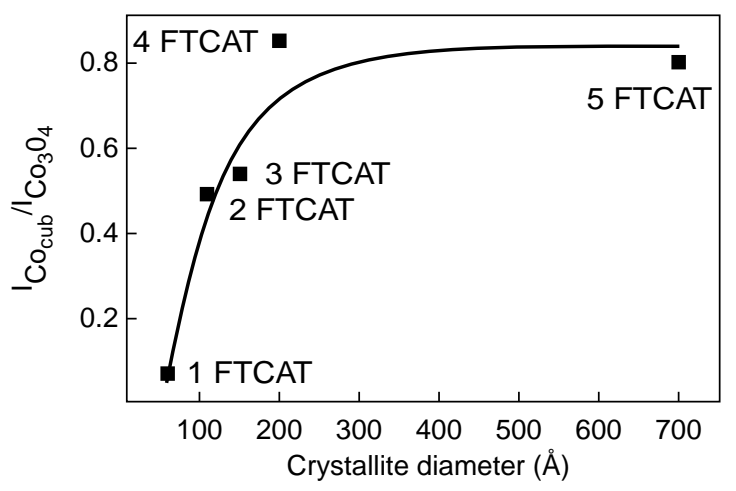

Figure 24

The fraction of reduced cobalt, shown by the ratio of Co metal to Co oxide XRD intensities, depends on the particle size, as determined from the XRD line width.

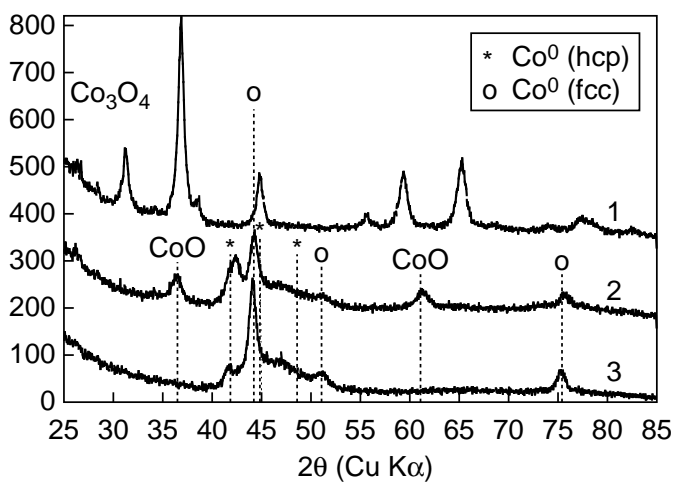

Figure 25

In situ XRD during the reduction of a silica supported $\mathrm{Co}_{3} \mathrm{O}_{4}$ catalyst. (1): starting oxide at $293 \mathrm{~K}$; (2): formation of the intermediate oxide $\mathrm{CoO}$ at $573 \mathrm{~K}$; (3): formation of metallic cobalt at $773 \mathrm{~K}$.

For certain conditions of preparation, the X-ray diffraction patterns show the presence of a quasi-amorphous phase (not 
identifiable by XRD) containing cobalt. The EXAFS signal is dominated by the cobalt contained inside large particles, making analysis of a minority phase by this technique particularly difficult. As another result of the large particle size, we were not able to detect bonds between surface cobalt and reactive gases under reaction conditions. Due to the particle morphology, EXAFS is in this case not very surface sensitive.

Here it is infrared spectroscopy using the $\mathrm{CO}$ molecule as a probe of the cobalt surface (IR(CO)) which allowed us to detect and characterise cobalt ions, dispersed on the support oxide, which are difficult to reduce (Fig. 26). The use of probe molecules to explore a solid confers inherent sensitivity to surface sites.

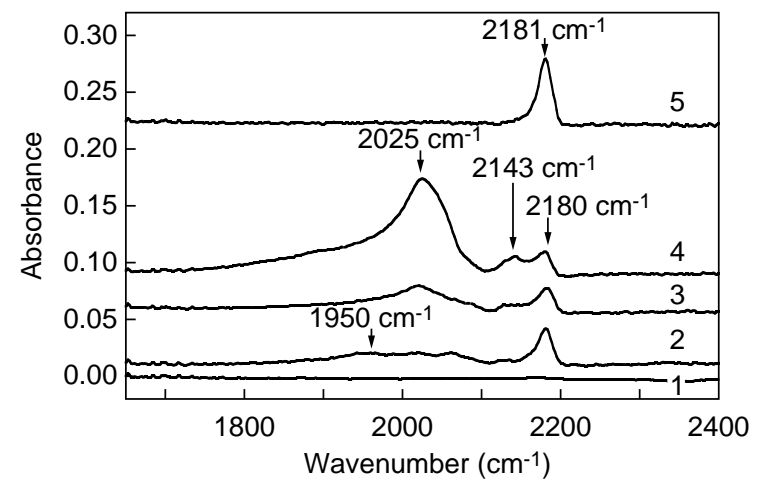

Figure 26

Infrared vibration spectra of molecular $\mathrm{CO}$ absorbed on (1) silica and (2 to 5) on various reduced $\mathrm{Co} / \mathrm{SiO}_{2}$ catalysts. Vibration bands are due to absorption on metallic cobalt at 1950 and $2025 \mathrm{~cm}^{-1}$, on the intermediate oxide $\mathrm{CoO}$ at $2143 \mathrm{~cm}^{-1}$, and on a non-reducible oxide at $2181 \mathrm{~cm}^{-1}$.

A technique for promoting this type of catalyst involves reduction to metallic cobalt, followed by passivation and impregnation with an aqueous solution containing a promoter. A subsequent increase in dispersion, activity and selectivity of the promoted phase is often attributed to the promoter element. We have applied this protocol using only water, without the promoter element [58]. The result is a redispersion of cobalt, as shown by the increase in the IR(CO) band attributed to dispersed cobalt species on the support (Fig. 27) and by a decrease in the quantity of $\mathrm{Co}_{3} \mathrm{O}_{4}$ particles measured by X-ray diffraction.

The short range order information from cobalt $\mathrm{K}$ edge EXAFS obtained during the process (Fig. 28) allows us to identify the critical step for redispersion. After passivation the EXAFS signal is similar to that of the reference cobalt metal. The signal is only slightly modified for a wet sample. Here the particles are certainly partially oxidised at the surface, but for these large particle sizes EXAFS is not sufficiently sensitive to detect the effect. The environment of cobalt is transformed during drying, with apparition of Co-O

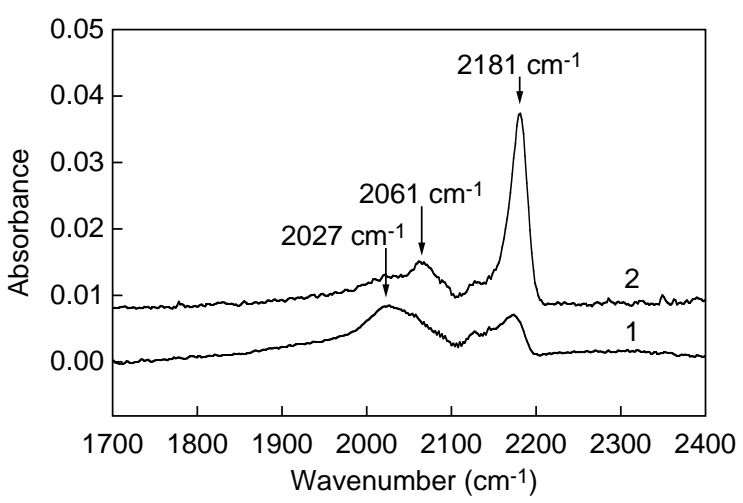

Figure 27

IR(CO) spectra before (1) and after (2) pure water treatment of a $\mathrm{Co} / \mathrm{SiO}_{2}$ catalyst. The increase in the band at $2181 \mathrm{~cm}^{-1}$ is attributed to a redispersion of cobalt over the support.

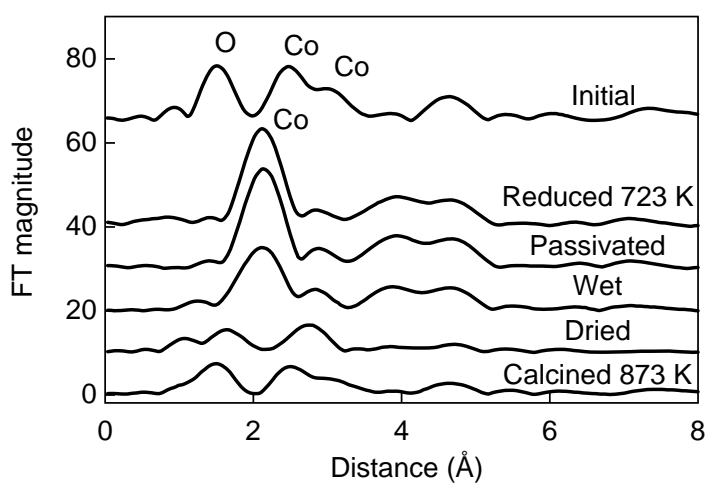

Figure 28

EXAFS allows the redispersion process of a $\mathrm{Co} / \mathrm{SiO}_{2}$ catalyst to be followed step by step (the sequence of treatments is from the top to the bottom of the figure). The structural reorganisation occurs during drying.

bonds. The local structure is however different to that of the stable oxide $\mathrm{Co}_{3} \mathrm{O}_{4}$, which only reappears after calcining. So it is the heating in a humid atmosphere that allows mobilisation of ionic cobalt species resulting in redispersion. Recalcining leads to the formation of $\mathrm{Co}_{3} \mathrm{O}_{4}$, with a lower signal compared to the starting oxide, probably due to the simultaneous formation of the dispersed amorphous phase.

These observations may have important consequences for the interpretation of variations in catalytic activity following promotion. They show that at least a part of the modifications in the performances, usually attributed to the presence of a promoter, could be explained by a change in the environment of the main element.

\subsection{Structure - Activity Relationships}

The adaptation of a reaction cell to the diffraction apparatus subsequently allowed us to follow the evolution of working 
Fischer-Tropsch catalysts [59]. Under reactions conditions the formation of a cobalt carbide phase $\mathrm{Co}_{2} \mathrm{C}$ is observed (Fig. 29).

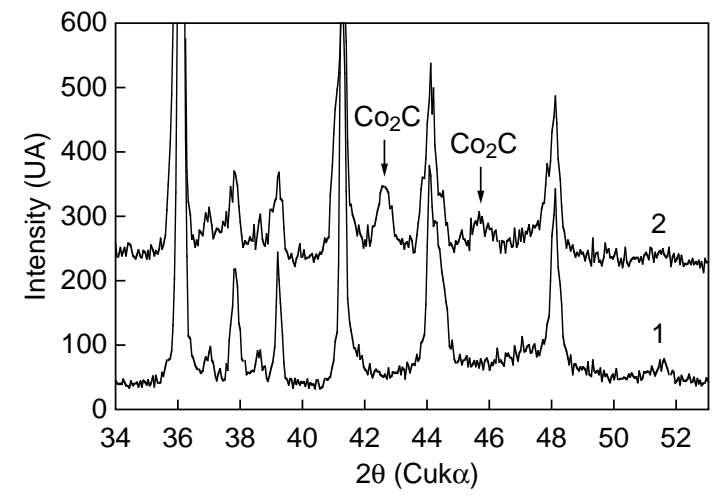

Figure 29

Diffraction patterns of a $\mathrm{Co} / \mathrm{TiO}_{2}$ catalyst: (1) after reduction under hydrogen; (2) after a $180 \mathrm{~h}$ test under synthesis gas $\left(\mathrm{T}=503 \mathrm{~K}, \mathrm{P}=3\right.$ bar, $\mathrm{H}_{2} / \mathrm{CO}=9$ ).

Coupled with a gas analysis system at the reactor outlet, XRD showed a direct correlation between the formation of this compound and modifications of the catalyst's activity and selectivity. Formation of the carbide phase is accompanied by a loss of activity but there is also a change in the product distribution of the Fischer-Tropsch reaction, which is oriented towards the production of long chain hydrocarbons (Fig. 30).

\subsection{The Need for a Multi-Technique Approach}

The studies of mixed oxide transformations and of cobalt redispersion illustrate the complimentary nature of the techniques of X-ray diffraction and absorption. A complete description of the structure of these types of solids requires both short and long range order information. The obvious potential interest of simultaneous analysis by these two techniques led to our participation in the creation of a new EXAFS-XRD beamline at the LURE synchrotron (beamline H10). The contribution of infrared spectroscopy of adsorbed $\mathrm{CO}$ to the study of Fischer-Tropsch catalysts is also noteworthy. IR(CO) spectroscopy presents an added interest for the study of these catalysts because the $\mathrm{CO}$ molecule is one of the reactant gas molecules. The possibility of adapting existing IR cells to allow in situ analyses is therefore now an active research topic.

\section{CONCLUSION}

Through the examples presented here we can identify some basic themes of research in the characterisation of industrial heterogeneous catalysts.

The various techniques considered differ in their fields of application and in the type of information provided. The choice of one or other technique or of a combination of techniques depending on the problem to be solved is thus of great importance.

For supported metals we are particularly interested in the dispersion and possible association of metals. Techniques presenting chemical selectivity (induced X-ray analysis in the TEM, EXAFS) are important in these cases. We have seen that analytical microscopy allows analysis in terms of composition and structure of particles a few nanometers in size on an individual basis. We reach the limits of this technique for highly dispersed reforming catalysts. Here, with particle sizes less than a nanometer, only EXAFS, with it's capacity to explore the environment of a specific element, is capable of providing relevant structural information.
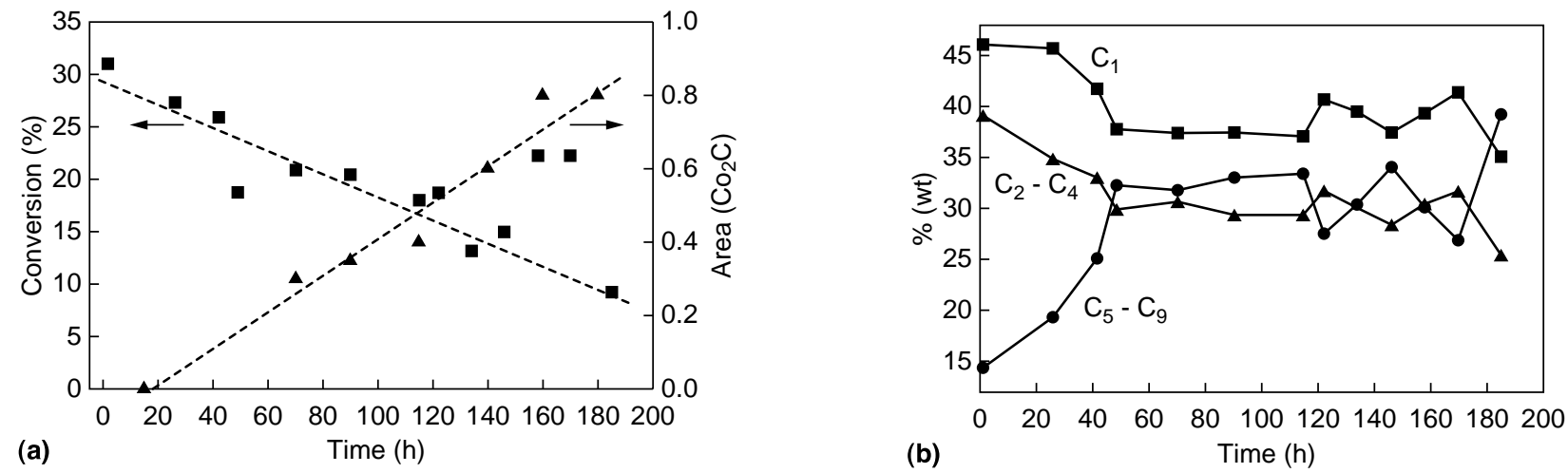

Figure 30

Correlation between structural evolution and changes in catalytic properties of a $\mathrm{CoRu} / \mathrm{TiO}_{2}$ catalyst under synthesis gas. (a): formation of the carbide phase (triangles) and CO conversion (squares); (b): simultaneous reaction product analysis. 
For zeolites the principal problem addressed was the distribution of aluminium between different sites within and outside the framework. Although with the TEM we can explore the texture at the scale of a few nanometers, techniques with the possibility of discriminating structural differences at the angstrom scale (XRD, NMR) are needed here. Quantitative information from X-ray diffraction allowed us to follow the distribution of extra-framework species in solids submitted to different treatments.

The more recent studies of reactivity of mixed oxides and Fischer-Tropsch catalysts involved following both structural modifications and metal/support interactions; access to two types of information, chemical and structural, was necessary. Coupling information from different analysis techniques or, better, the possibility to analyse the same specimen at the same time is indispensable to obtain a global vision of the system. This is illustrated by our use of combined XRD/DER and EXAFS in the first case, XRD and infrared spectroscopy in the second.

Another research direction is the adaptation of techniques, where possible, to allow in situ studies of catalysts under conditions close to those of their utilisation so as to obtain information on their reactivity and to come within reach of the catalytically active form. Global analysis techniques, in particular those based on the use of photons in the X-ray and infrared ranges, are particularly good sources of in situ information.

We have been able to establish a correlation between the structure of a solid and it's reactivity in several cases. The resistance to sulphur poisoning of bimetallic catalysts and the lack of sensitivity of the catalytic performance of zeolite based catalysts to the presence of some extra-framework species were related to the structure of these solids. Ideas for research into the origins of the high thermal stability of mixed oxides and into the effect of promotion in FischerTropsch catalysts have been proposed. For the latter system a direct correlation between structural modifications under reaction conditions and variations in catalytic activity and selectivity has been established.

The examples presented here show only some of the recent developments in tools for catalyst characterisation. The use of these techniques are being continuously improved, both in the laboratory and in synchrotron radiation centres, promising new approaches to characterisation and access to significantly new information on catalyst structure. In situ use of characterisation techniques is now acknowledged as vital (see for example the recent collection of articles in [60]). The limits to the application to industrial catalysts are not yet clearly defined, making these new approaches an active research area.

The information we are able to gather on the electronic state of atoms in catalysts is for the moment incomplete. Although it is possible to differentiate the oxide form from the metallic state of an element, techniques such as XPS and
EELS do not have the resolution required to study for instance the effects of alloy formation at the nanometer scale. Attempts to extract this type of information via infrared spectroscopy of adsorbed molecules have revealed difficulties in the interpretation of data. We recently started an exploratory study in soft X-ray spectroscopy of external electronic shells which holds great promise in terms of resolution and sensitivity to electronic state. Figure 31 shows an application of cobalt $\mathrm{L}_{\mathrm{III}}$ edge spectroscopy to FischerTropsch catalysts. Redispersion of cobalt by contacting the passivated solid with water leads to an edge shape similar to that observed in compounds such as $\mathrm{CoO}$ and $\mathrm{Co}_{2} \mathrm{SiO}_{4}$, characteristic of an octahedral $\mathrm{Co}^{2+}$ environment, very different from the $\mathrm{Co}_{3} \mathrm{O}_{4}$ environment in the starting catalyst. A reaction cell attached to the soft X-ray beamline allowed us to follow the changes in the environment of cobalt during reduction under hydrogen [61].

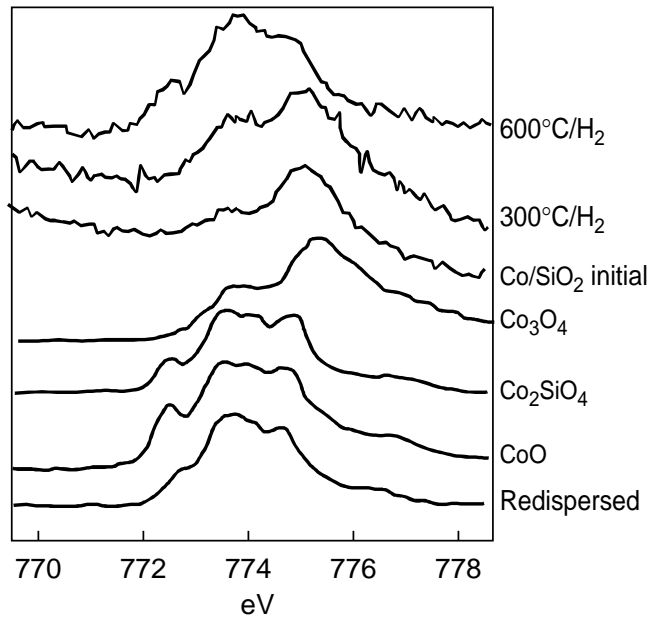

Figure 31

Cobalt $\mathrm{L}_{\mathrm{III}}$ edges of reference compounds and of FischerTropsch catalysts. Changes in the edge shape for a $\mathrm{Co} / \mathrm{SiO}_{2}$ catalyst can be followed as a function of reduction temperature under hydrogen.

In nuclear magnetic resonance, new so called "multiquantum" impulse sequences give a more detailed view of the environment of quadrupolar nuclei such as aluminium. We have shown that it is now possible to clearly separate the various extra-framework species in stabilised zeolites [62].

Using the combined effects of energy dependant X-ray absorption and X-ray diffraction (in the technique known as anomalous diffraction) information on long range order can be obtained for specific target atoms. We have successfully applied this technique to the problem of locating two cations ( $\mathrm{K}$ and $\mathrm{Ba}$ ) present simultaneously in a zeolite molecular sieve. An extension to other types of solid, in particular to mixed sulphides, is an exciting prospect. 
As a final note, we should remember that researchers in a wide variety of petroleum related domains can profit from the new techniques described here and the advances in their application. X-ray absorption spectroscopy has found applications ranging from following modifications in sulphur environment during pyrolysis of kerogens [63] to the study of interactions between lubrication additives for motor oil [64]. Mastering the effects of interactions between radiation and matter served as a basis for developments in multiphase flow metering systems to monitor the composition of production fluids [65] and in microtomography [66] for the visualisation of texture in reservoir rocks and composite materials [67].

The availability of such an impressive arsenal of techniques has also imposed both a reflection on what it is that each technique "sees", and a need for a clear formulation of the questions to which we seek answers. Our experience tells us that these interrogations often lead to a new impetus to adapt the available techniques, and thus to new information on the structure and reactivity of complex systems.

\section{ACKN O W LEDG EMEN TS}

The author wishes to express his gratitude to co-workers at $I F P$, in particular B. Rebours, N. Zanier, S. Gautier and J.C. Roussel, to colleagues P. Lagarde, H. Dexpert and D. Bazin of the Laboratoire d'utilisation du rayonnement électromagnétique, université Paris XI, and to all those who contributed to this project as doctoral and postdoctoral students: E. Rosenberg, X. Montagne, E. Merlen, N. Somorjai Guyot-Sionnest, A. Bensaddik, A. Gola, O. Ducreux, A. Caballero, M. Bellotto, A. Khodakov and E. Milazzo.

\section{REFEREN CES}

1 Lynch, J.P. and Brown, L.M. (1982) Systematic Errors in Thickness Measurement by Grigson Microdiffraction. Inst. Phys. Conf. Ser., 61, 249-250.

2 Lynch, J.P., Brown, L.M. and Jacobs, M.H. (1980) Ageing Sequence of Al-1.2 wt\% $\left(\mathrm{Mg}_{2} \mathrm{Si}\right)$ Studied by Microdiffraction. Inst. Phys. Conf. Ser., 52, 345-346.

3 Lynch, J.P., Brown, L.M. and Jacobs, M.H. (1982) Microanalysis of Age-Hardening Precipitates in Aluminium Alloys. Acta Metall., 30, 1389-1395.

4 Spence, J.C.H. and Lynch, J.P. (1982) STEM Microanalysis by Transmission Electron Energy Loss Spectroscopy in Crystals. Ultramicroscopy, 9, 267-276.

5 Dexpert H., Freund, E. and Lynch, J.P. (1981) Characterisation of Supported Metal Catalysts using STEM, in Quantitative microanalysis with high spatial resolution, Lorimer, G.W., Jacobs, M.H. and Doig, P. (eds.), The Metals Soc., London, 101-107.

6 Lynch, J.P., Lesage, E., Dexpert, H. and Freund, E. (1982) Microdiffraction of Industrial Supported Catalysts. Inst. Phys. Conf. Ser., 61, 67-70.
7 Lynch, J.P., Dexpert, H. and Freund, E. (1982) Applications of Microdiffraction with a STEM Instrument in Studies of Heterogeneous Catalysts. Scanning Electron Microscopy, 2, 517-522.

8 Lynch, J.P., Dexpert, H., Freund, E. and Pennycook, S.J. (1982) Applications of STEM in Solid State Chemistry. Inst. Phys. Conf. Ser., 61, 209-214.

9 Dexpert H., Freund, E. and Lynch, J.P. (1981) STEM applications to Microcrystalline Solids. J. Microsc. Spectrosc. Electron., 6, 627-635.

10 Freund, E., Lynch, J. and Szymanski, R. (1986) Small Particles in the Field of Industrial Supported Catalysts. Ultramicroscopy, 20, 107-118.

11 Freund, E. and Lynch, J. (1984) Applications of STEM to Problems in Heterogeneous Catalysis, in Heterogeneous Catalysis, Shapiro, B. (ed), Texas A\&M Univ. Press, Texas, 283-314.

12 Argile, C. and Lynch, J. (1988) Morphologie de cristallites de palladium sur support d'alumine. Rev. Inst. francais $d u$ pétrole, 43, 2, 245-259.

13 Occelli, M.L., Senders, J.V. and Lynch, J. (1987) TEM Analysis of Pillared and Delaminated Hectorite Catalysts. J. Catal., 107, 557-565.

14 Lynch, J., Raatz, F. and Dufresne, P. (1987) Characterisation of the Textural Properties of Dealuminated HY Forms. Zeolites, 7, 333-340.

15 Caullet, P., Hazm, J., Guth, J.L., Joly, J.F., Lynch, J. and Raatz, F. (1992) Synthesis of Zeolite Beta from NonAlkaline Fluoride Aqueous Aluminosilicate Gels. Zeolites, 12, 240-250.

16 Ajot, H., Joly, J.F., Lynch, J., Raatz, F. and Caullet, P. (1991) Formation of Secondary Pores in Zeolites during Dealumination: Influence of the Cristallographic Structure and of the Si/Al ratio. Studies in Surf. Sci. and Catal., 62, 583-590.

17 Dexpert, H., Lesage, E., Freund, E. and Lynch, J.P. (1982) Étude par microdiffraction électronique des relations cristallographiques métal-support : cas du système $\mathrm{Pd} / \mathrm{Al}_{2} \mathrm{O}_{3}$, in Metal-Support and Metal-Additive Effects in Catalysis, Imelik, B. et al. (eds), Elsevier Scientific, Amsterdam, 53-61.

18 Montagne, X., Lynch, J., Freund, E., Lamotte, J. and Lavalley, J.C. (1987) A study of the Adsorption Sites on Thoria by STEM and FTIR Spectroscopy. Adsorption and Desorption of Water and Methanol. J. Chem. Soc. Farad. Trans. 1, 83, 1417-1425.

19 Lynch, J. and Szymanski, R. (1985) Applications du STEM en catalyse hétérogène. J. Microsc. Spectrosc. Electron., 10, 485-490.

20 Lynch, J.P. (1984) X-ray Emission Spectroscopy of Industrial Catalysts in the STEM. J. de Physique, 45, C2701-C2-704.

21 Szymanski, R. and Lynch, J. (1986) Quantitative X-ray Microanalysis of Divided Solids in the STEM, in Proceedings of the 11th International Conference on X-Ray Optics and Microanalysis, Brown, J.D., Packwood, R.H. (eds), Univ. W. Ontario Press, Ottawa, 412-415.

22 Szymanski, R. and Lynch, J. (1988) The Advantages of Ultramicrotomy for Large Scale Correlations of TEM/STEM Analyses of Industrial Heterogeneous Catalysts. Inst. Phys. Conf. Ser., 93, 295-296. 
23 Szymanski, R. and Lynch, J. (1989) Specimen Limitations in Nano-Characterisation by TEM/STEM of Industrial Heterogeneous Catalysts. Ultramicroscopy, 28, 295-301.

24 Freund, E., Dexpert, H. and Lynch, J.P. (1983) Perspectives et limitations de la microscopie électronique appliquée à l'étude des milieux très dispersés : exemple des catalyseurs hétérogènes, in Microscopie électronique en science des materiaux, Jouffrey, B., Bourret, A. and Colliex, C. (eds), Editions du CNRS, Paris, 425-440.

25 Szymanski, R. and Lynch, J. (1988) TEM/STEM Characterisation of Industrial Type Supported Pd Catalysts: effect of an in situ Hydrogen Activation, in Proceedings of the 46th Annual EMSA Meeting, Bailey, G.W. (ed), San Francisco Press, 700-701.

26 Lynch, J.P. (1984) Distribution du courant dans des sondes limitées par l'aberration sphérique. J. Micros. Spectros. Electron., 9, A26.

27 Lynch, J.P. (1983) Microdiffraction by Highly Dispersed Catalyst Particles. J. Micros. Spectrosc. Electron., 8, 481488.

28 Dexpert, H., Freund, E. and Lynch, J.P. (1982) Sensitivity Limits in X-Ray Emission Spectroscopy of Catalysts. Inst. Phys. Conf. Ser., 61, 171-174.

29 Roch, I., Boitiaux, J.P., Lynch, J., Szymanski, R., Buffat, Ph. and Rutherana, P. (1989) HREM and STEM Study of the Genesis of Pd-Fe Bimetallic Catalysts. J. Microsc. Spectrosc. Electron., 14, 43a.

30 Lynch, J. (1994) Characterisation of Industrial Catalysts by EXAFS. Journal de Physique III, 4, C9-253-C9-259.

31 Lynch, J. and Maire, G. (1993) Catalyse hétérogène et SOLEIL, in Projet SOLEIL : argumentation scientifique, Chandesris, D., Morin, P. and Nenner, I. (eds), Les Éditions de Physique, Les Ulis, 173-178.

32 Bazin, D., Dexpert, H., Guyot-Sionnest, N.S., Bournonville, J.P. and Lynch, J. (1989) EXAFS Characterisation of Reforming Catalysts: Examples of Recent Applications. J. Chim. Phys., 86, 1707-1717.

33 Sayers, D.E., Cantrell, J., Bazin, D., Dexpert, H., Fontain, A., Lagard, P., Lynch, J. and Bournonville, J.P. (1989) Dispersive XAS Studies of the Reduction Kinetics of a Highly Dispersed Supported Catalyst. Physica B, 158, 206207.

34 Bazin, D., Dexpert H. and Lynch J. (1996) In situ XAFS Measurement of Catalysts. in X-Ray Absorption Fine Structure for Catalysts and Surfaces, Iwasawa, Y. (ed.) World Scientific Pub., Singapore, 113-129.

35 Berdala, J., Freund, E. and Lynch, J. (1986) Environment of Platinum Atoms in a $\mathrm{H}_{2} \mathrm{PtCl}_{6} / \mathrm{Al}_{2} \mathrm{O}_{3}$ Catalyst: Influence of Metal Loading and Chlorine Content. J. de Physique, 47, C8269-C8-270.

36 Bournonville, J. P. (1979) Étude de la recristallisation de platine dans un catalyseur de reformage. Thèse, université Paris 6.

37 Berdala, J., Freund, E. and Lynch, J. (1986) Genesis of the Metallic Phase in a Highly Dispersed Catalyst formed from Pt Acetylacetonate on Alumina. J. de Physique, 47, C8-265C8-266.

38 Vasudevan, S. (1982) Obtention et étude de catalyseurs palladium supporté à dispersions élevées. Thèse, université Paris 6.

39 Guyot-Sionnest, N.S., Bazin, D., Lynch, J., Bournonville, J.P. and Dexpert, H. (1989) First Experiments under High
Temperature and High Pressure on Reforming Catalysts. Physica B, 158, 211-212

40 Guyot-Sionnest, N.S., Villain, F., Bazin, D., Dexpert, H., Lepeltier, F., Lynch, J. and Bournonville, J.P. (1991) In situ High Temperature and High Pressure EXAFS Studies of $\mathrm{Pt} / \mathrm{Al}_{2} \mathrm{O}_{3}$ Catalysts. Catalysis Lett., 8, 283-296 and 297-304.

41 Lynch, J., Szymanski, R. and Charcosset, H. (1990) Characterisation by EXAFS and Electron Microdiffraction of Supported Pt-Zr Bimetallic Catalysts, in Progress in X-Ray Synchrotron Radiation Research, Balerna, A., Bernieri, E. and Mobilio, S. (eds), Società Italiana di Fisica, Bologna, 571-574.

42 Caballero, A., Dexpert, H., Didillon, B., LePeltier, F., Clause, O. and Lynch, J. (1993) In situ X-ray Absorption Spectroscopic Study of a Highly Dispersed $\mathrm{PtSn} / \mathrm{Al}_{2} \mathrm{O}_{3}$ Catalyst. J. Phys. Chem., 97, 11283-11285.

43 Caballero, A., Dexpert, H., LePeltier, F., Didillon, B. and Lynch, J. (1993) Study by EXAFS and TEM of the Effect of Reduction-Oxidation Cycles on $\mathrm{Pt} / \mathrm{Al}_{2} \mathrm{O}_{3}-\mathrm{K}$ and $\mathrm{PtSn} / \mathrm{Al}_{2} \mathrm{O}_{3}$ K Catalysts. Jap. J. Appl. Phys. Pt 1, 32, 442-444.

44 Caballero, A., Villain, F., Dexpert, H., LePeltier, F., Didillon, B. and Lynch, J. (1993) In situ EXAFS Studies of Modifications to Supported Metallic Catalysts under Reactive Atmospheres. Catalysis Lett., 20, 1-13.

45 Bazin, D., Dexpert, H., Bournonville, J.P. and Lynch, J. (1989) Bimetallic Catalysts: Oxydation as a Function of the Platinum to Second Metal Ratio. Physica B, 158, 154-155.

46 Bazin, D., Dexpert, H., Bournonville, J.P. and Lynch, J. (1990) Bimetallic Reforming Catalysts: EXAFS Investigation of the Particle Growth Process during the Reduction Step. J. Catal., 123, 86-97.

47 Caballero, A., Dexpert, H., LePeltier, F., Didillon, B. and Lynch, J. (1993) Characterisation by in situ EXAFS Spectroscopy of $\mathrm{Pt} / \mathrm{Al}_{2} \mathrm{O}_{3}$ and $\mathrm{PtRe} / \mathrm{Al}_{2} \mathrm{O}_{3}$ Catalysts under Reaction Conditions. Jap. J. Appl. Phys. Pt 1, 32, 439-441.

48 Caballero, A., Villain, F., Dexpert, H., LePeltier, F. and Lynch, J. (1993) In situ EXAFS Study of the Effect of Hydrocarbon Deposition over $\mathrm{Pt} / \mathrm{Al}_{2} \mathrm{O}_{3}$ and $\mathrm{Pt}-\mathrm{Re} / \mathrm{Al}_{2} \mathrm{O}_{3}$ Catalysts. J. Chem. Soc. Farad. Trans., 89, 159-164.

49 Bensaddik, A., Dexpert, H., Bazin, D., Caballero, A., Villain, F., Didillon, B. and Lynch, J. (1995) In situ Study by XAS of the Sulfuration of the $\mathrm{Pt}$ and $\mathrm{PtRe} / \mathrm{Al}_{2} \mathrm{O}_{3}$ Systems. Physica $B$, 208 and 209, 677-678.

50 Bensaddik, A., Caballero, A., Bazin, D., Dexpert, H., Didillon, B. and Lynch, J. (1997) In situ Study by XAS of the Sulphidation of Industrial Catalysts: the Pt and $\mathrm{PtRe} / \mathrm{Al}_{2} \mathrm{O}_{3}$ Systems. Applied Catal. A, 162, 171-180.

51 Merlen, E., Baerlocher, Ch., Espinat, D., Lynch, J. and Raatz, F. (1989) Textural and Structural Characterisation of Dealuminated Y Zeolite, in Zeolites: Facts, Figures, Future (Proc. 8th Int. Zeolite Conf. Amsterdam, July 10-14) Jacobs, P.A. and van Santen, R.A. (eds) Elsevier, Amsterdam, 187188.

52 Merlen, E., Lynch, J., Bisiaux, M. and Raatz, F. (1990) Surface Modifications during Y Zeolite Dealumination. Surf. Interface Anal., 16, 364-368.

53 Benazzi, E., Lynch, J., Gola, A., Lacombe, S. and Marcilly, Ch. (1998) Controlled Removal of Extra-Framework Aluminium Species in USY Zeolite, in Proceedings 12th Int. Zeolite Conf. Baltimore July 5-10, Treacy, M.M.J., Marcus, B.K., Bisher, M.E. and Higgins, J.B. (eds), Materials Research Society, Warrendale, 2735-2742. 
54 Benazzi, E., Lynch, J., Gola, A. and Marcilly, Ch. (1998) Influence of Extra-Framework Aluminium Species on the Activity and Selectivity of $\mathrm{Y}$ Zeolites in $n$-Decane Hydrocracking, in Proceedings 12th Int. Zeolite Conf. Baltimore July 5-10, Treacy, M.M.J. Marcus, B.K., Bisher, M.E. and Higgins, J.B. (eds), Materials Research Society, Warrendale, 1011-1017.

55 Bellotto, M., Rebours, B., Clause, O., Lynch, J., Bazin, D. and Elkaim, E. (1996) A Re-Examination of Hydrotalcite Crystal Chemistry. J. Phys. Chem., 100, 8527-8534

56 Bellotto, M., Rebours, B., Clause, O., Lynch, J., Bazin, D. and Elkaim, E. (1996) Hydrotalcite Decomposition Mechanism: a Clue to the Structure and Reactivity of Spinellike Mixed Oxides. J. Phys. Chem., 100, 8535-8542.

57 Khodakov, A., Lynch, J., Bazin, D., Rebours, B., Zanier, N., Moisson, B. and Chaumette, P. (1997) Reductibility of Co Species in Silica Supported Fischer Tropsch Catalysts. J. Catal., 168, 16-25.

58 Khodakov, A., Ducreux, O., Lynch, J., Rebours, B. and Chaumette, P. (1999) Structural Modification of Cobalt Catalysts: Effect of Wetting Studied by X-Ray and Infrared techniques. Oil \& Gas Science and Technology - Revue de l'IFP, 54, 525-536.

59 Ducreux, O., Lynch, J., Rebours, B., Roy, M. and Chaumette, P. (1998) In situ Characterisation of Cobalt Based FischerTropsch Catalysts: a New Approach to the Active Phase. Studies in Surf. Sci. and Catal., 119, 125-130.
60 Topics in Catalysis (1999), 8, issue 1/2, 1-140.

61 Bazin, D., Parent, P., Laffon, C., Ducreux, O., Lynch, J., Kovacs, I., Guczi, L. and de Groot, F. (1999) Following the Reduction under $\mathrm{H}_{2}$ of Supported Cobalt Catalysts through the L Absorption Edges. J. Synchrotron Rad., 6, 430-432.

62 Gola, A., Rebours, B., Milazzo, E., Lynch, J., Benazzi, E., Lacombe, S., Delevoye, L. and Fernandez, C. (2000) Effect of Leaching Agent in the Dealumination of Stabilized Y Zeolites. Microporous and Mesoporous Materials, 40, 73-83.

63 Lynch, J., Everlien, G., Leblond, C. and Bazin, D. (1999) Evolution of Sulfur during Pyrolysis of Petroleum Kerogens. J. Synchrotron Rad., 6, 661-663.

64 Mansuy, H. (1995) Étude des interactions entre additifs antiusure et dispersants. Influence sur la formation des films limites. Thèse, université Paris VI.

65 Lynch, J. (1991) Techniques de débitmétrie polyphasique non intrusive. Rev. Inst. français du pétrole, 46, 59-88.

66 Ferreira de Paiva, R., Bisiaux, M., Lynch, J. and Rosenberg, E. (1996) High Resolution X-Ray Tomography in an Electron Microprobe. Rev. Sci. Instrum., 67, 2251-2256.

67 Rosenberg, E., Lynch, J., Guérault, P., Bisiaux, M. and Ferreira de Paiva, R. (1999) High Resolution 3D Reconstruction of Rocks and Composites. Oil \& Gas Science and Technology - Revue de l'IFP, 54, 497-512.

Final manuscript received in January 2002 